تأثير نانوذرات اكسيد آهن عاملدار و كود شيميايى سولفات روى بر گونهبندى روى در خاك و جذب روى در كندم

\author{
على عبدالهى'، مجتبى نوروزى مصير '،."، مهى تقوى ' و عبدالامير معزى'

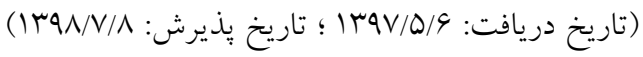

جكيده

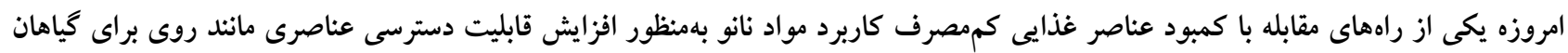

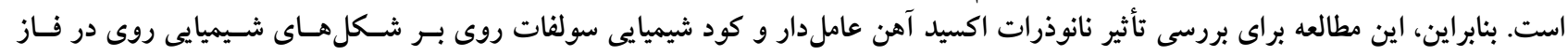

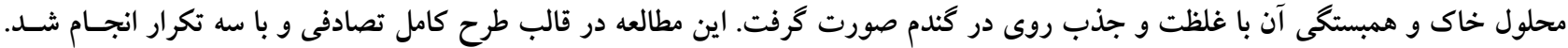

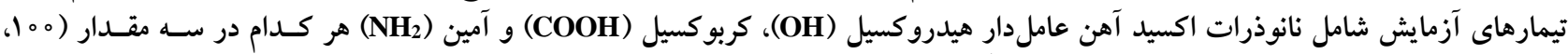

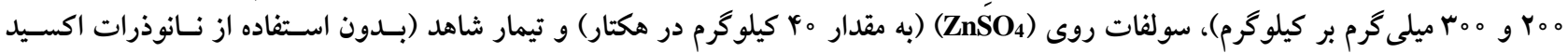

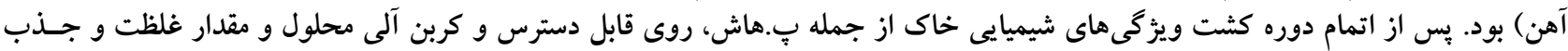

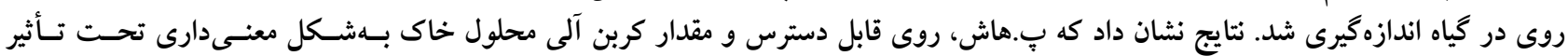

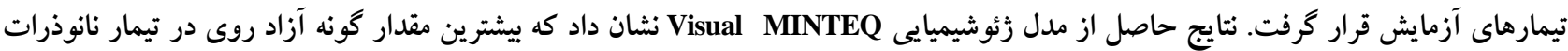

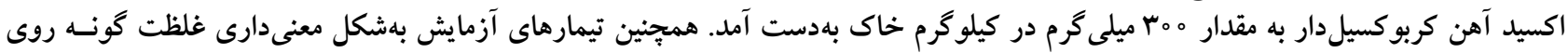

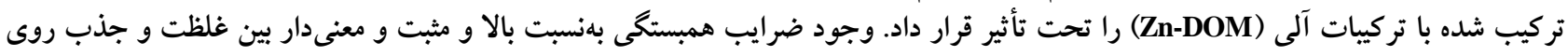

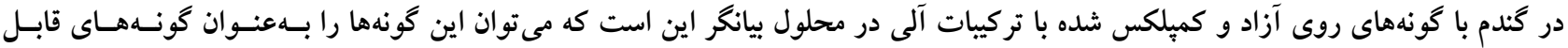

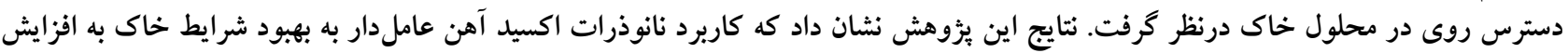
قابليت دسترسى روى كمك مى كند.

وازمهاى كليدى: نانوذرات، كربن آلى محلول، كود شيميايى، عناصر كمصرف

ا ا. گروه علوم خاك، دانشكده كثاورزى، دانشخاه شهيد خمر ان اهواز

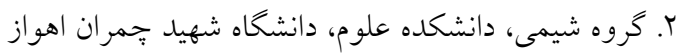

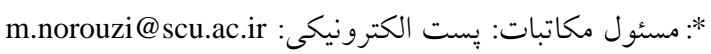


زيستمحيطى اعـم از خـاك و آب، بـهـــار گيرى روشهــاى

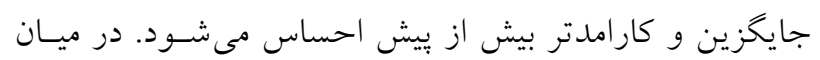

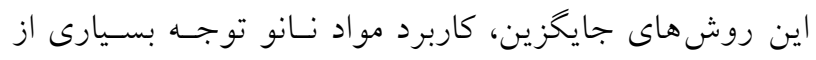

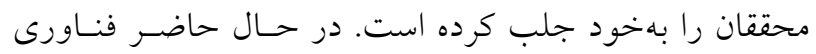

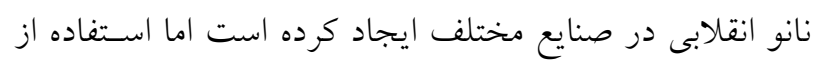
آن در صنعت كشاورزى مراحل اوليه خود را سبرى مسى كنــا.

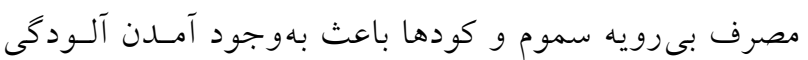

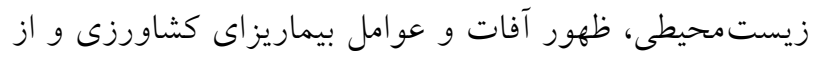
دست رفتن تنوع زيستى مىشود؛ فناورى نانو بهواسطه داشتن

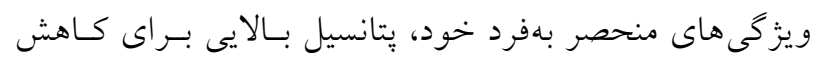
اين مشكلات دارد (11). برخى محققان بيان كردند كه ويزَى هاى فيزيكى - شيميايى

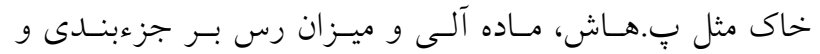

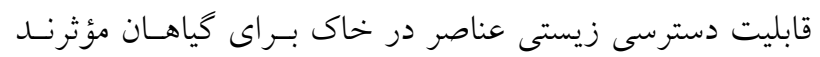
(T M M T). و اكنشهاى اصلى نانوذرات در سيستم خاك- كياه،

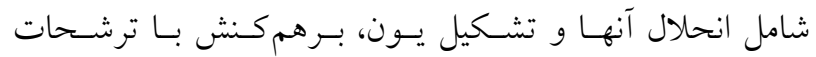

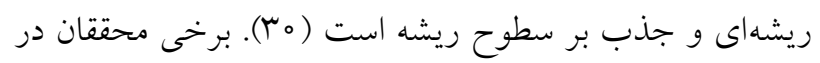

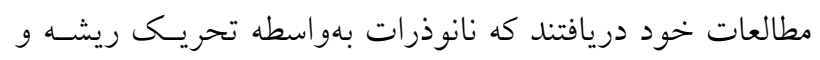

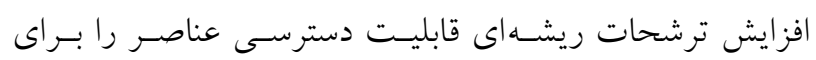

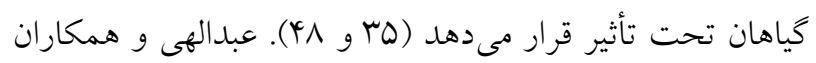

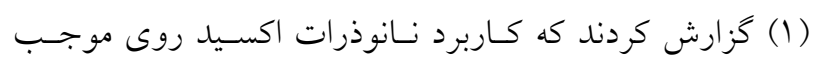

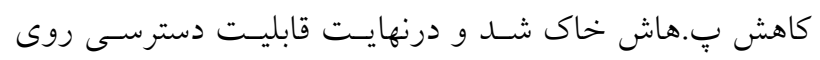

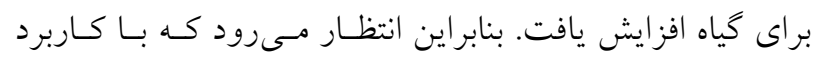

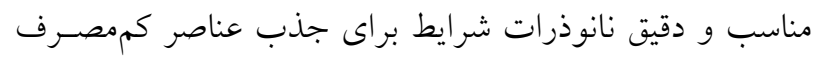
در منطقه ريزوسفر ريشه فراهم شود.

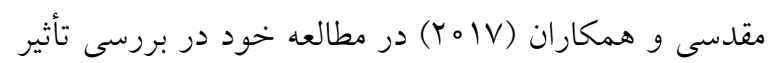

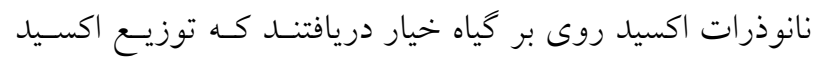

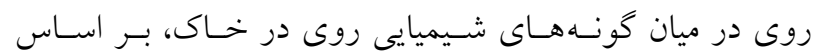

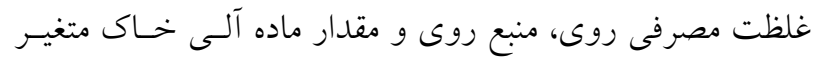

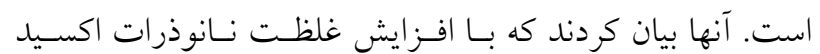
روى، روى ييونديافته بـا اكسـيدهاى آهـن و منخخنز و كربناتـهـ

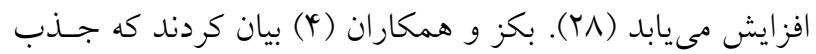

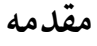

كرسنكى ينهان يا كمبود مو اد غذايى كممصرف موجب به تأخير

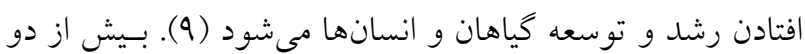

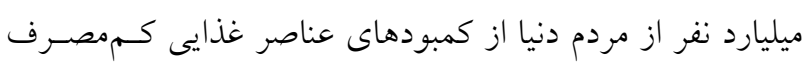

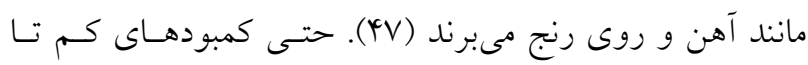

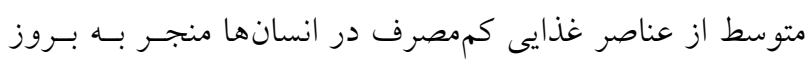

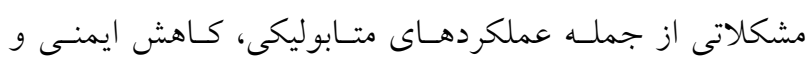

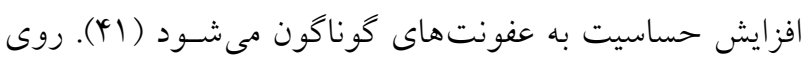

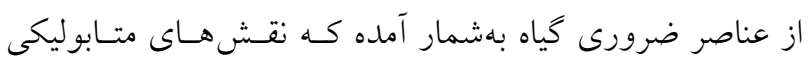

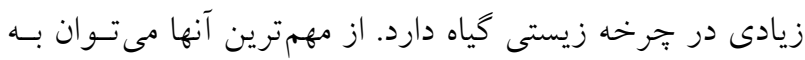

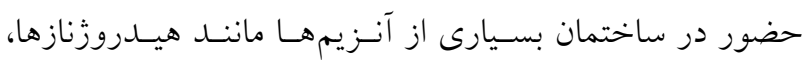

يروتئينازها، يتيدازها و فسفوهيدرولازها اشاره كرد (TV).

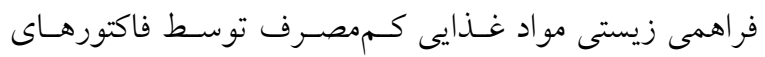

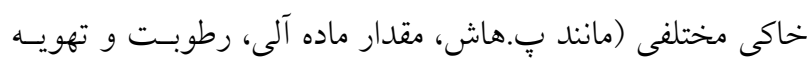

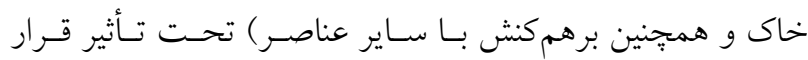

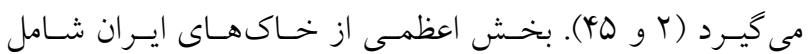

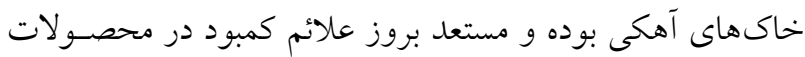

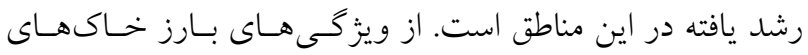
آهكى كمبود عناصر كممصرف مانند روى اسـت. بِ.هـاش بـاتلا،

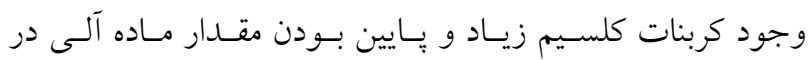

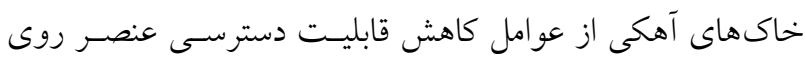

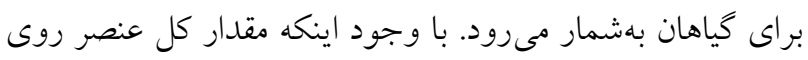

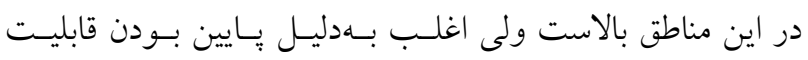

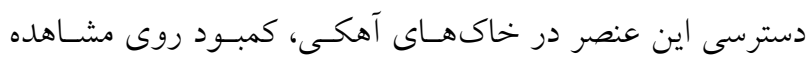

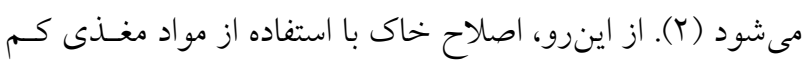

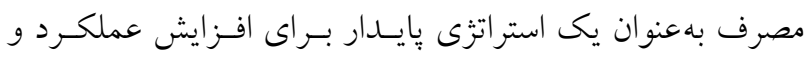

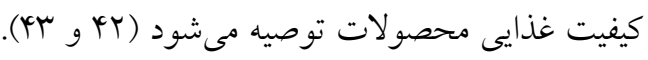

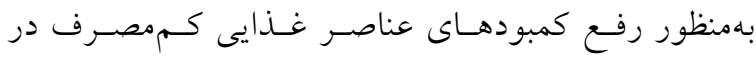

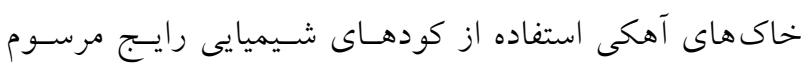

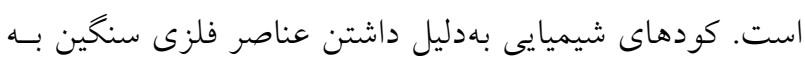

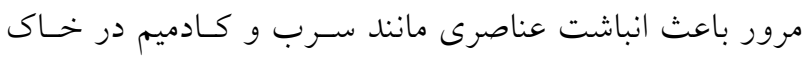

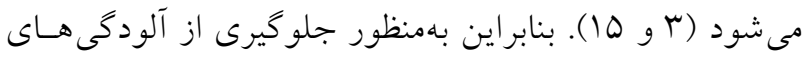


قرائت شد (YY). خاك مورد آزمايش بر اساس حد بحرانى كمبود

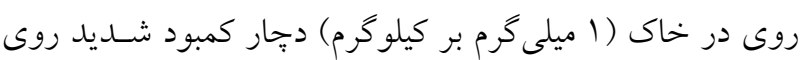

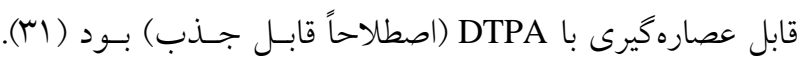

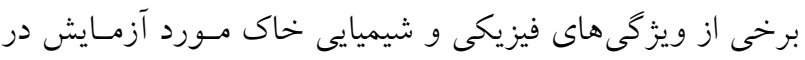
جدول ا ارائه شده است. اين بزوهش در كلخانه تحقيقاتى دانشكده كشاورزى دانشگاه شهيد جمران اهواز در قالب طرح كامل تصادفى و در سـه تكـرار

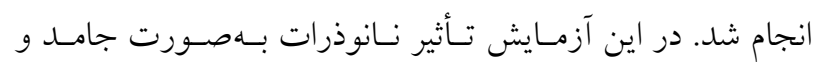
تركيب شده بـا خـاك روى گنــدم (Triticum aestivum L) رقـم جمران مورد بررسى قرار گرفت. مقدار كـود شـيميايى سـولفات

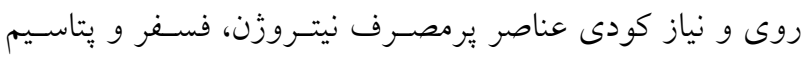

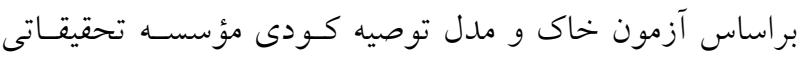
خاك و آب محاسبه و اعمال شد (Y)).

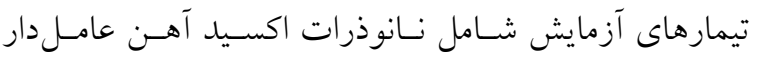

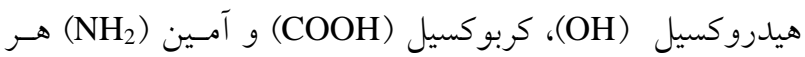

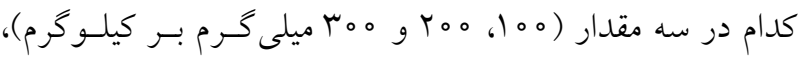

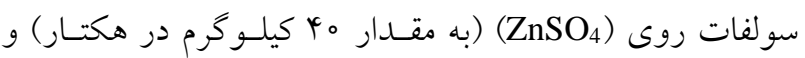
تيمار شاهد (بدون استفاده از نانوذرات اكسيد آهن) بـوداد. سـتنتز

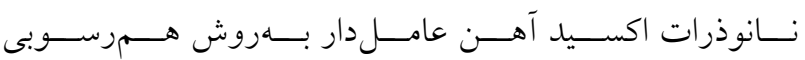
(Co-precipitation)

\section{تهيه نانوذرات اكسيد آهن (Fe3)} نانوذرات اكسيد آهن با استفاده از روش متداول همرسوبى تهيه شدند. ابتدا /Yه خرم

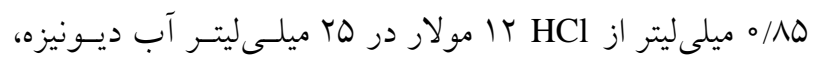

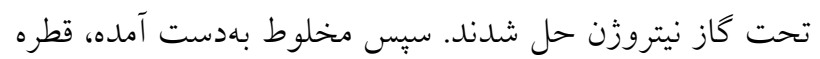

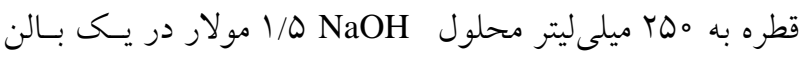

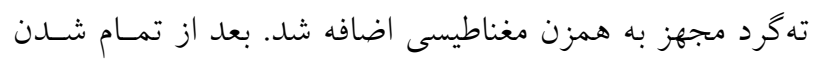

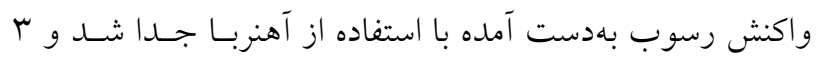

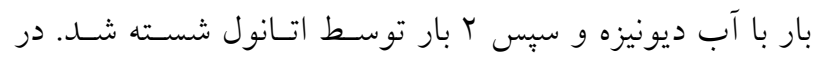
نهايت نانوذرات

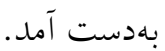

فلزات از خاك توسط كياه به گونه كل و محلول فلز و همجنين

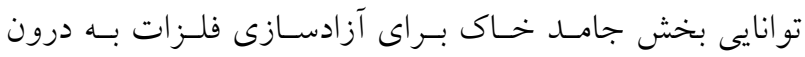

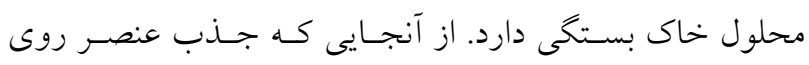

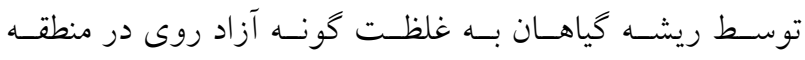
ريزوسفر ارتباط دارد (19)، مىتوان كفت كه غلظـت و و قابليـت دسترسى روى در محلول خاى براى كياه بيشتر بهواسطه روابط ريط

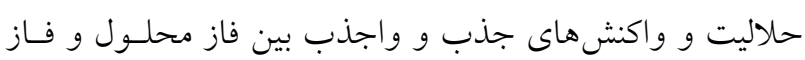

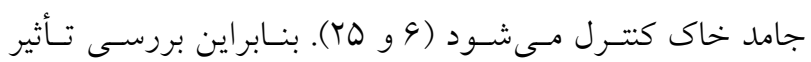
نانوذرات مختلف بر شكلهاى شيميايى مختلف عناصـر فلـزى

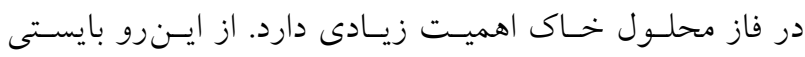

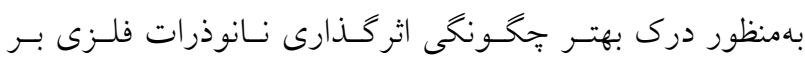

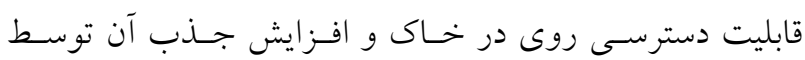

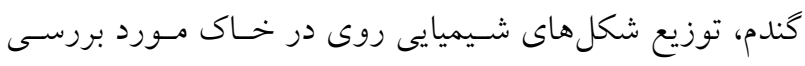

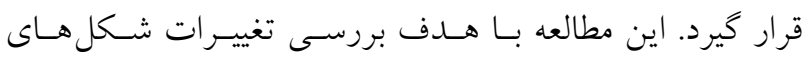

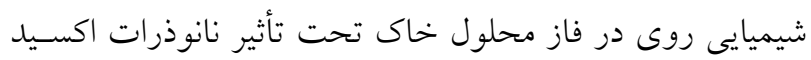

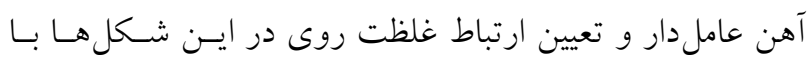
غلظت و جذب روى در كندم انجام شد.

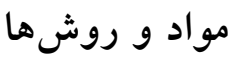

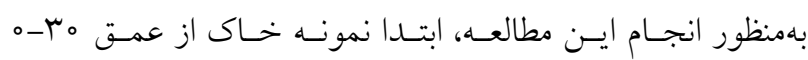

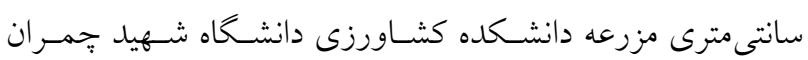

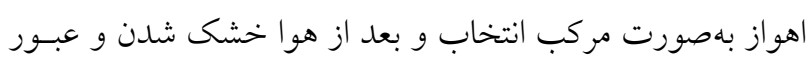

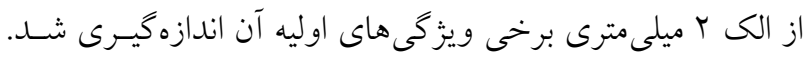

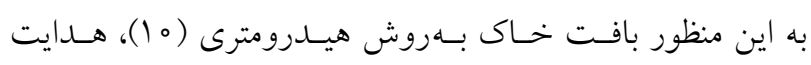

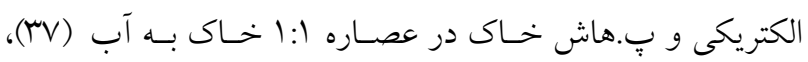

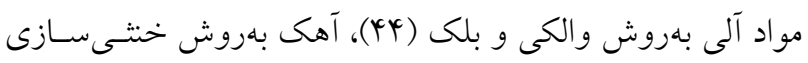

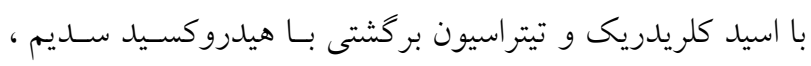

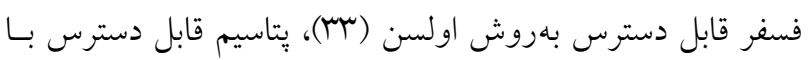

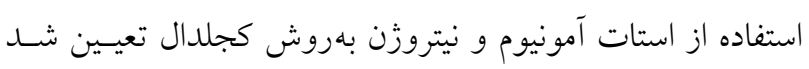

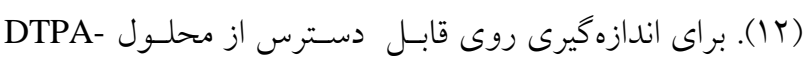

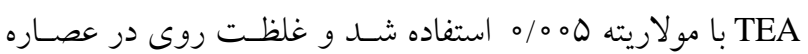

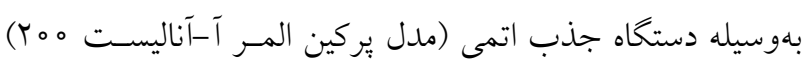


جدول ا. برخى ويزگى هاى فيزيكى و شيميايى خاك مورد مطالعه

\begin{tabular}{|c|c|c|c|c|c|c|c|}
\hline هدايت الكتريكى & بֶ.هاش & ن نيتروزن & فسفر قابل دسترس & يتاسيم قابل دسترس & روى قابل دسترس & ماده آلى & بافت خاك \\
\hline $\mathrm{dS} . \mathrm{m}^{-1}$ & - & $(\%)$ & & $\left(\mathrm{mg} . \mathrm{kg}^{-1}\right)$ & & $(\%)$ & - \\
\hline$r / \Delta$ & $\mathrm{V} / \mathrm{A}$ & $\circ / \circ \mathrm{V}$ & $V / \mathrm{I}$ & rq。 & $\circ / \Delta \Delta$ & $\circ / V_{1}$ & لوم-رسى \\
\hline
\end{tabular}

در طول دوره رشد گياه، با استفاده از آبيـارى سـطحى رطوبـت

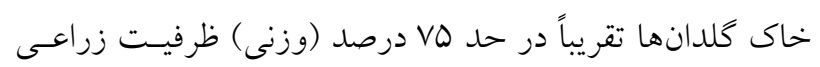

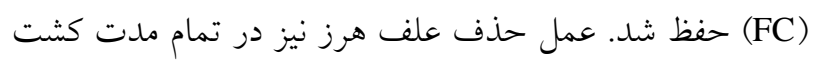

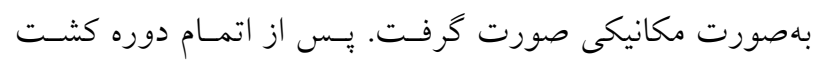

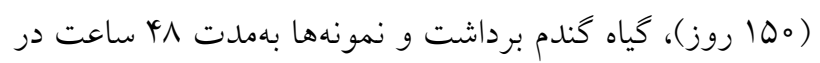

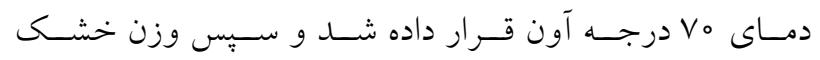

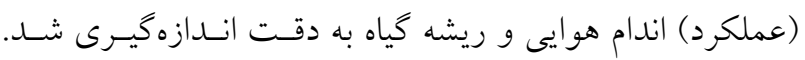

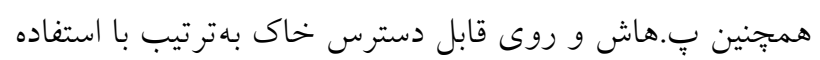

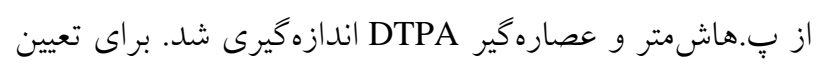

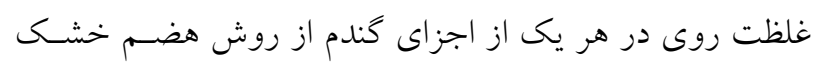

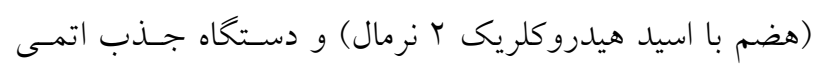

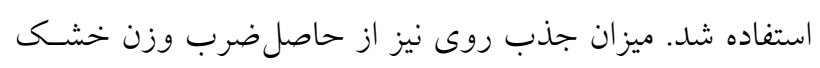

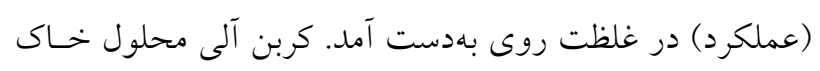

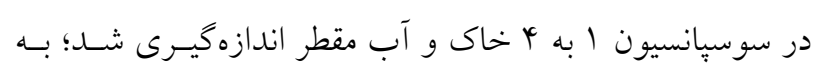

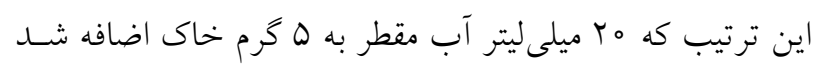

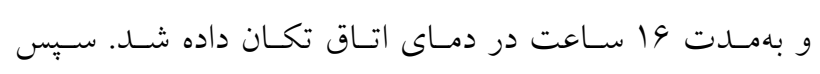

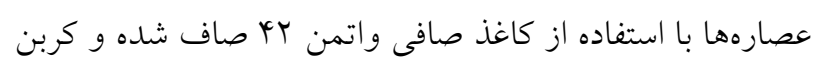

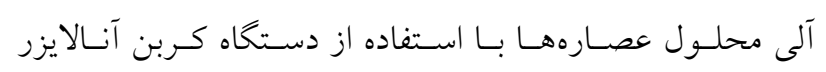
اندازهكيرى شد (19) (19).

براى استخراج عناصـر و تعسين كونسهــاى روى در در فـاز

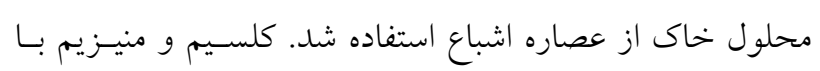

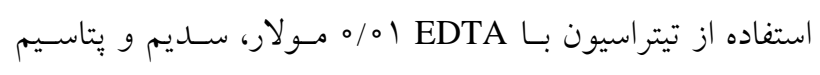

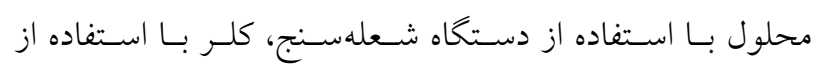

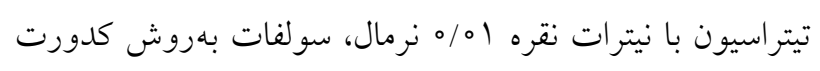

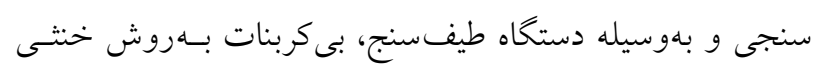

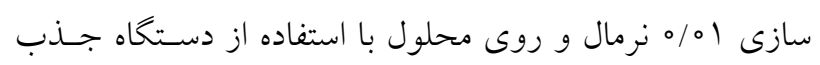

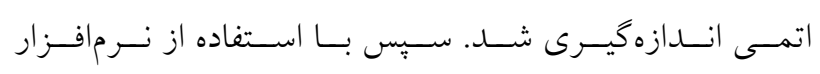

تهيه نانوذرات آهن نيتروزندار $\left(\mathrm{Fe}_{3} \mathrm{O}_{4}-\mathrm{NH}_{2}\right)$

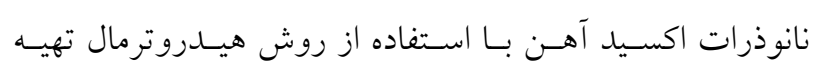

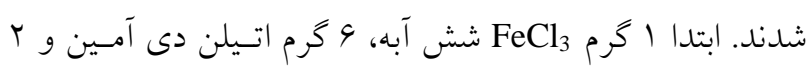

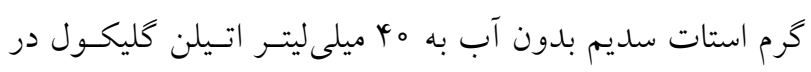

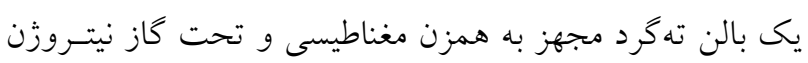

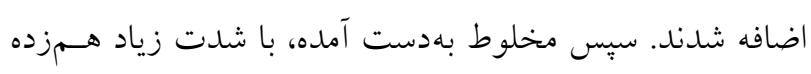

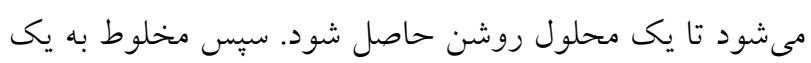

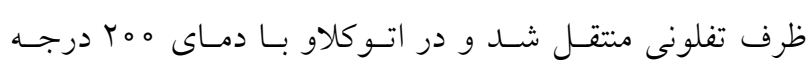

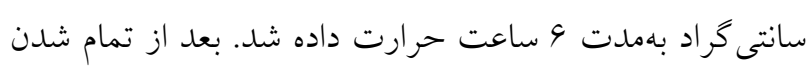

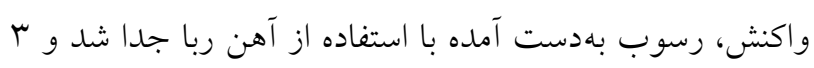

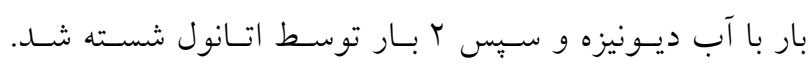
درنهايت نانوذرات

\section{تهيسه نـانوذرات آهـن كربو كسـيل دار $\left(\mathrm{Fe}_{3} \mathrm{O}_{4}\right.$ و و سولفونيك اسيد $\left(\mathrm{Fe}_{3} \mathrm{O}_{4}-\mathrm{SO}_{3} \mathrm{H}\right)$}

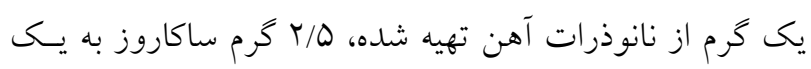

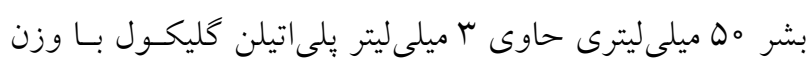

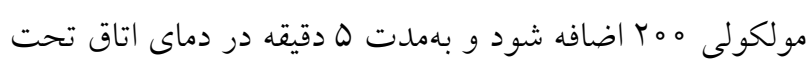

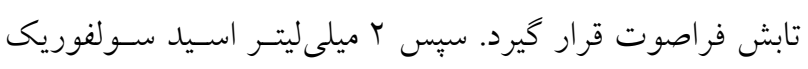

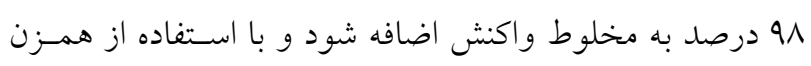

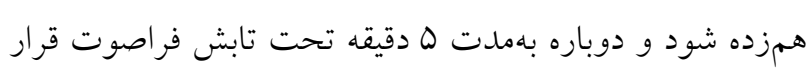

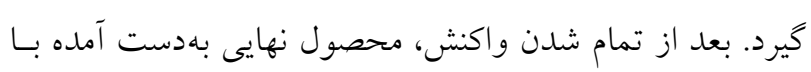

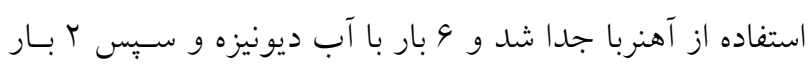

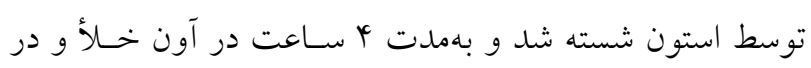
دماى اتاق خشك شد.

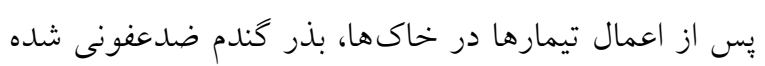

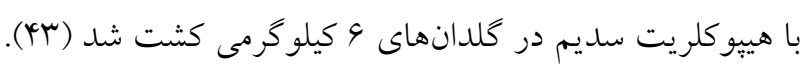




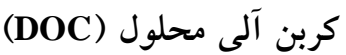
نتايج حاصل از تجزيه واريانس نشان داد كـه تـأثير نـانوذرات

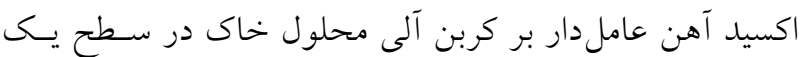
درصد معنى دار بود (جدول Y). به استثناى نـانوذرات اكسيد

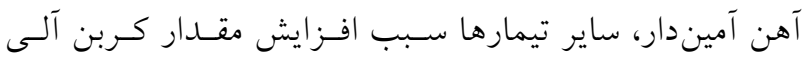
محلول (// آ درصد تا بيش از Y برابر) در مقايسـه بـا تيمـار

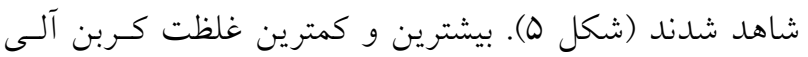

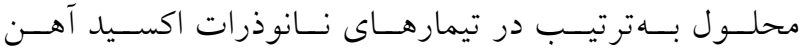

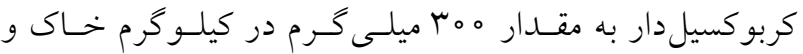
شاهد مشاهده شد (شكل ه).

\section{روى قابل دسترس خاك}

نتايج تجزيه واريانس در جدول ب نشان مىدهد كه تأثير تيمارها روى قابل دسترس خاك در سطح يـك درصــ معنسىدار بـود.

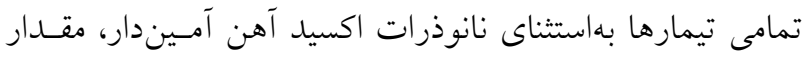

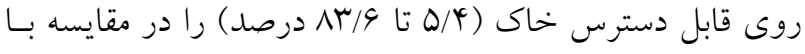
تيمار شاهد افزايش دادند (شكل 9). بيشترين غلظت روى قابـل دسترس خاك در تيمار نانوذرات اكسيد آهـن كربو كسيلـدار در

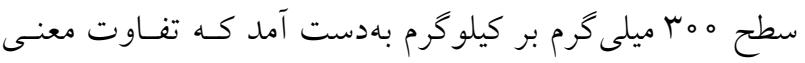

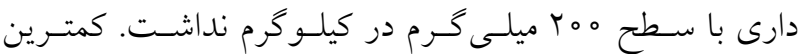
غلظت روى قابل دسترس خاك در تيمـار شـاهد مشـاهده شـــ

نانوذرات اكسيد آهن عامـلدار بــدليـل داشـتن گــروهـــاى عاملى منجر به تغييرات ب..هاش خاك شدند. وجود كروههـاى

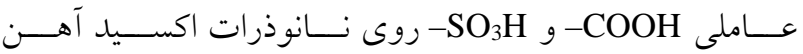
كربو كسيل دار موجب كاهش ب.هاش خاك شده است. ايسن دو كروه عاملى جزء اسيدهاى قوى بهشمار مىرونــــ و در مقايسـه با كروههاى عاملى OH- و NH2- قدرت اسيدى بيشترى دارند.

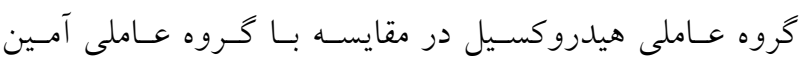

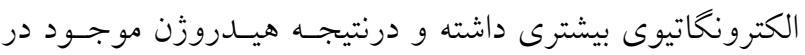

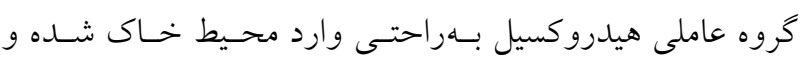
موجب كاهش ب..هاش خاك مىشود. گروه عاملى آمسين داراى
كونههاى روى در محلول خـاك بـيشبينى Visual MINTEQ

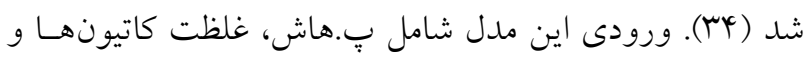

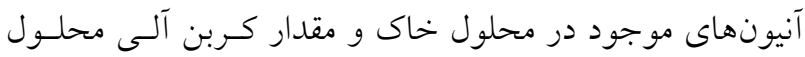

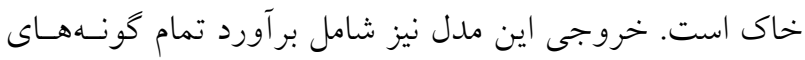
آزاد و كميلكس شده معلنى و آلى است.

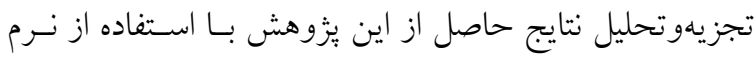

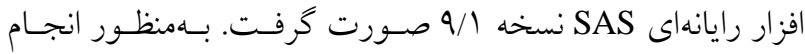

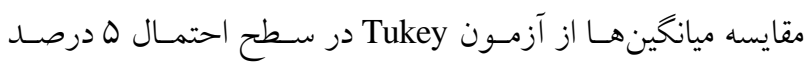
استفاده شد. رسم نمودارها نيز با استفاده از نرم افزار Excel انجـام

نتايج و بحث تعيين مورفولوزى نانوذرات اكسيد روى آناليز SEM براى مطالعه نحوه بر اكندگى نـانوذرات اكسـيد روى از دسـتحاه

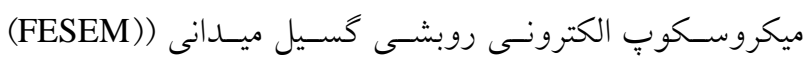
Field Emission Scanning Electron Microscopy

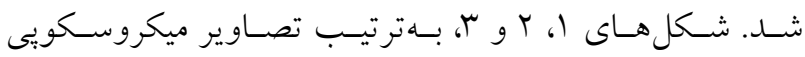

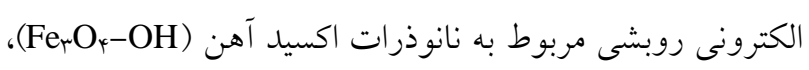

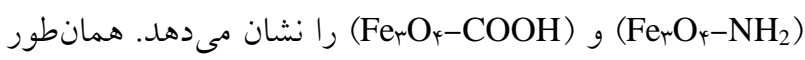

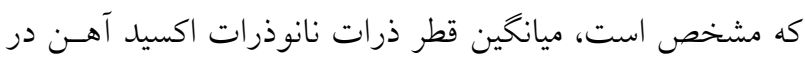

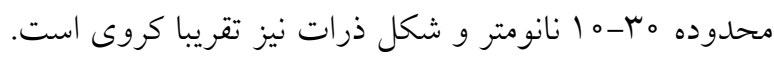

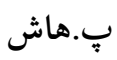
تأثير نانوذرات اكسيد آهن عامل دار بر بٍ.هاش خاى در سـطح

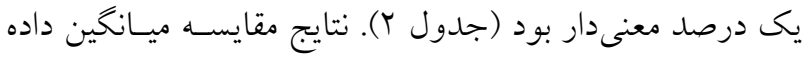

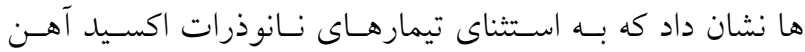

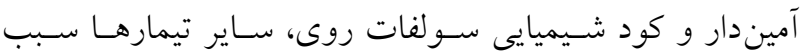

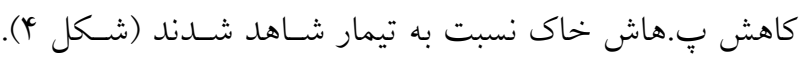

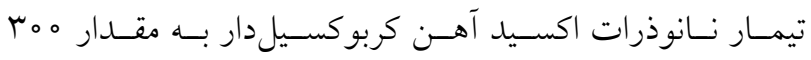

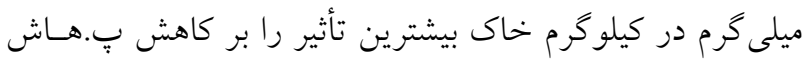

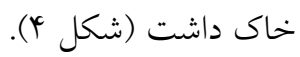


نشريه علوم آب و خاك / سال بيست و جهارم / شماره دوم / تابستان 99ه1

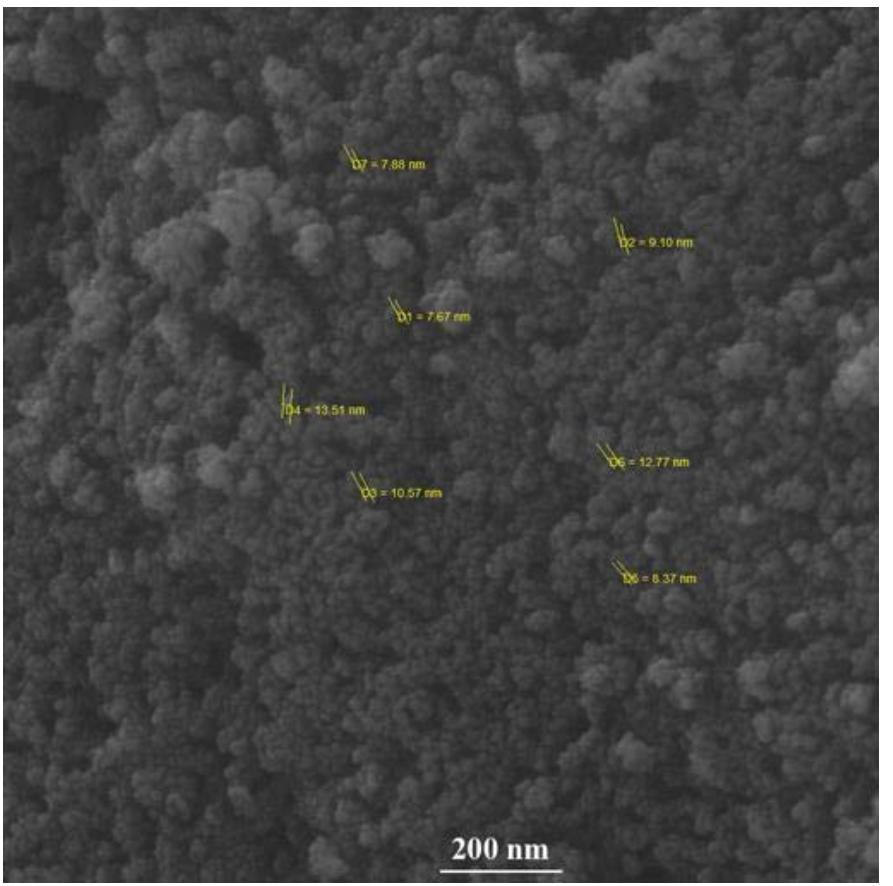

شكل ا. تصوير ميكروسكويى الكترونى روبشى گسيل ميدانى نانوذرات اكسيد آهن هيدروكسيلدار

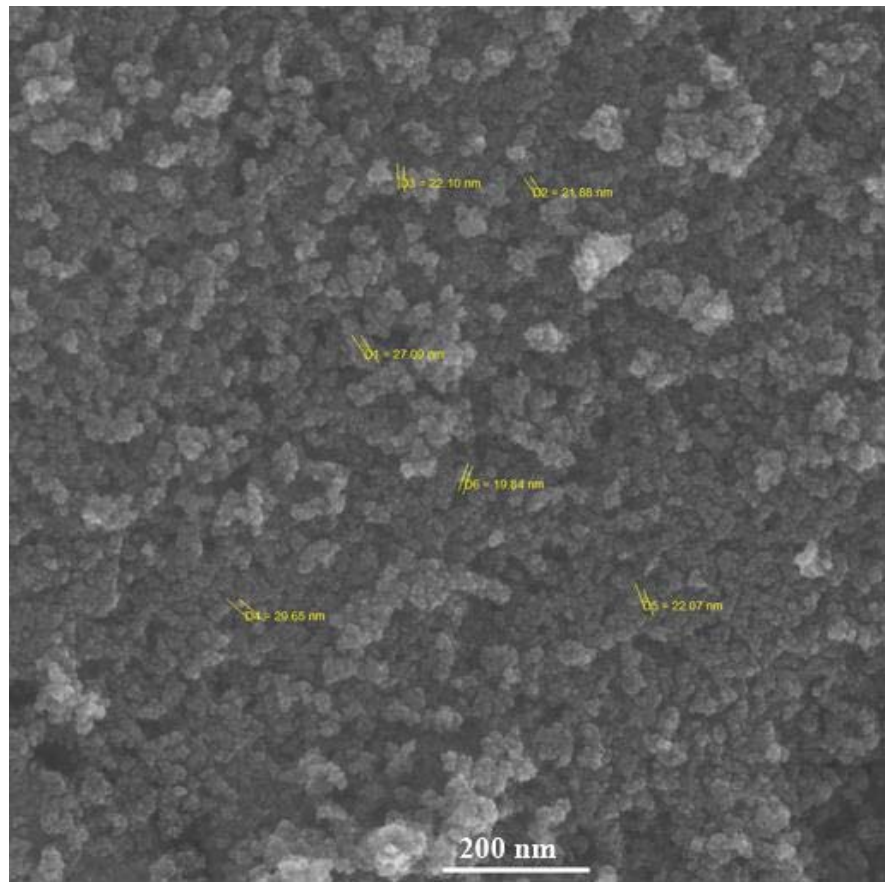

شكل r. تصوير ميكروسكويى الكترونى روبشى گسيل ميدانى نانوذرات اكسيد آهن آميندار 


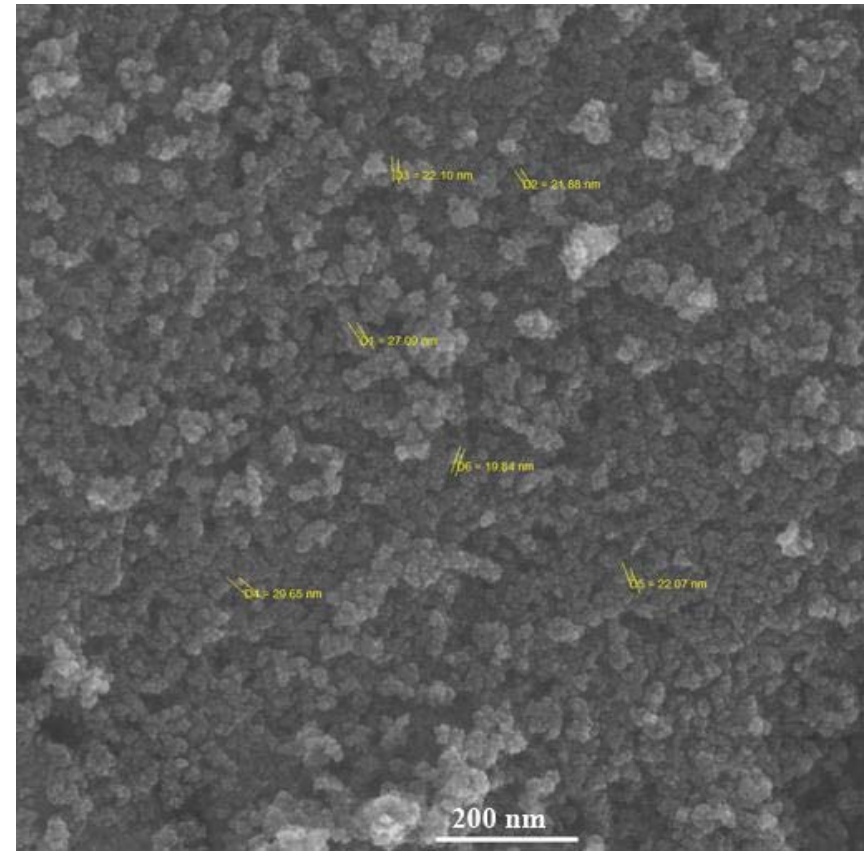

شكل r. تصوير ميكروسكويى الكترونى روبشى گسيل ميدانى نانوذرات اكسيد آهن كربوكسيلدار

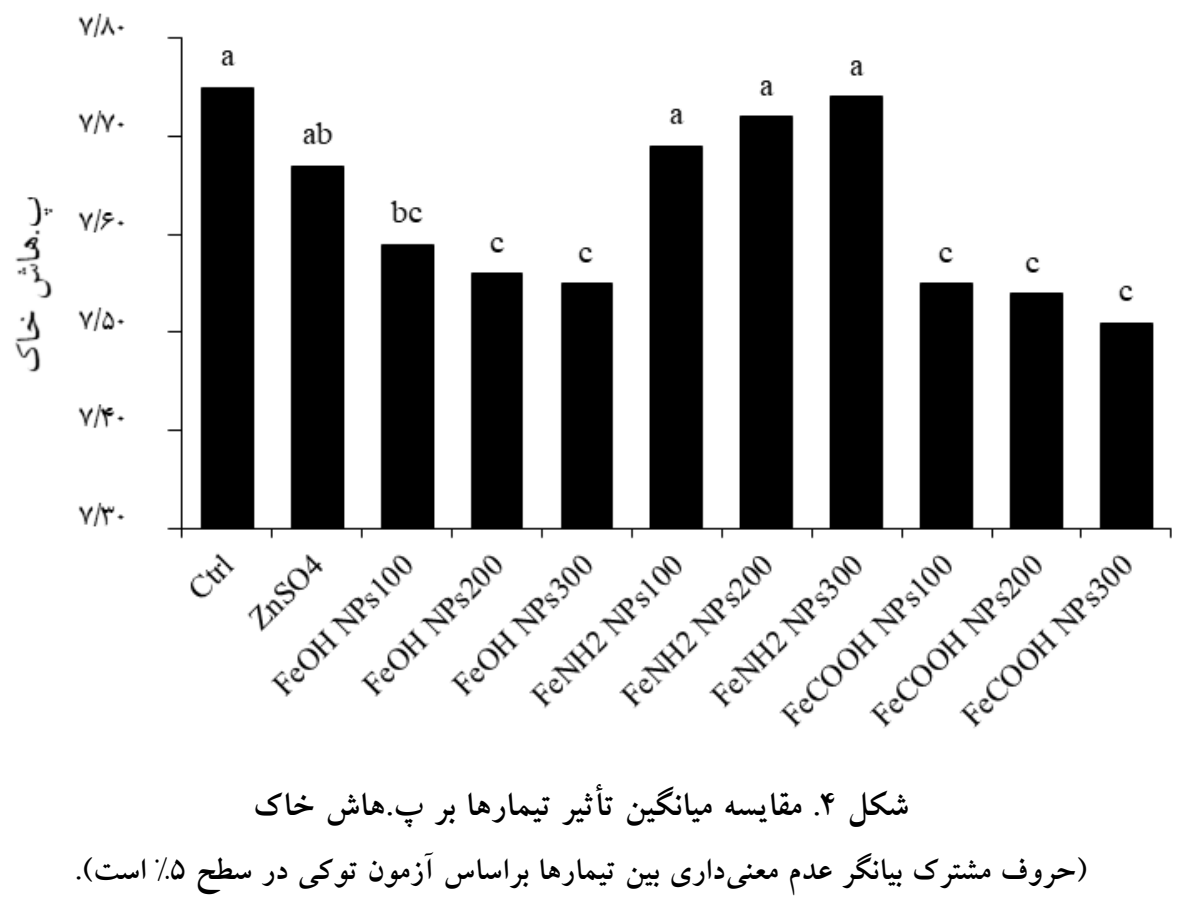

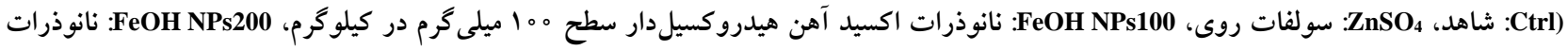

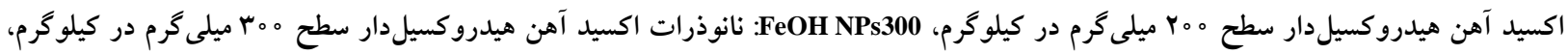

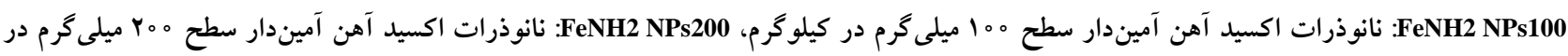

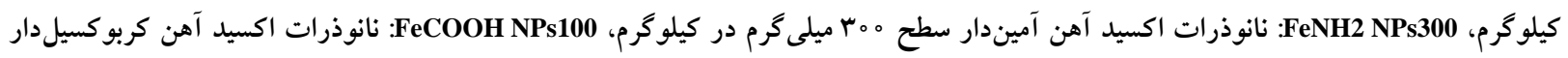

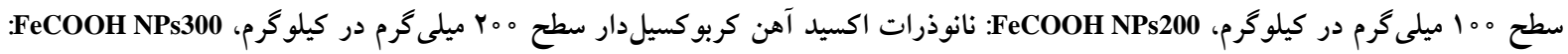

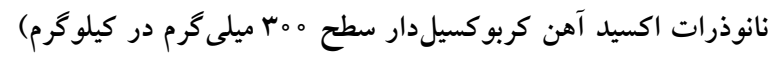




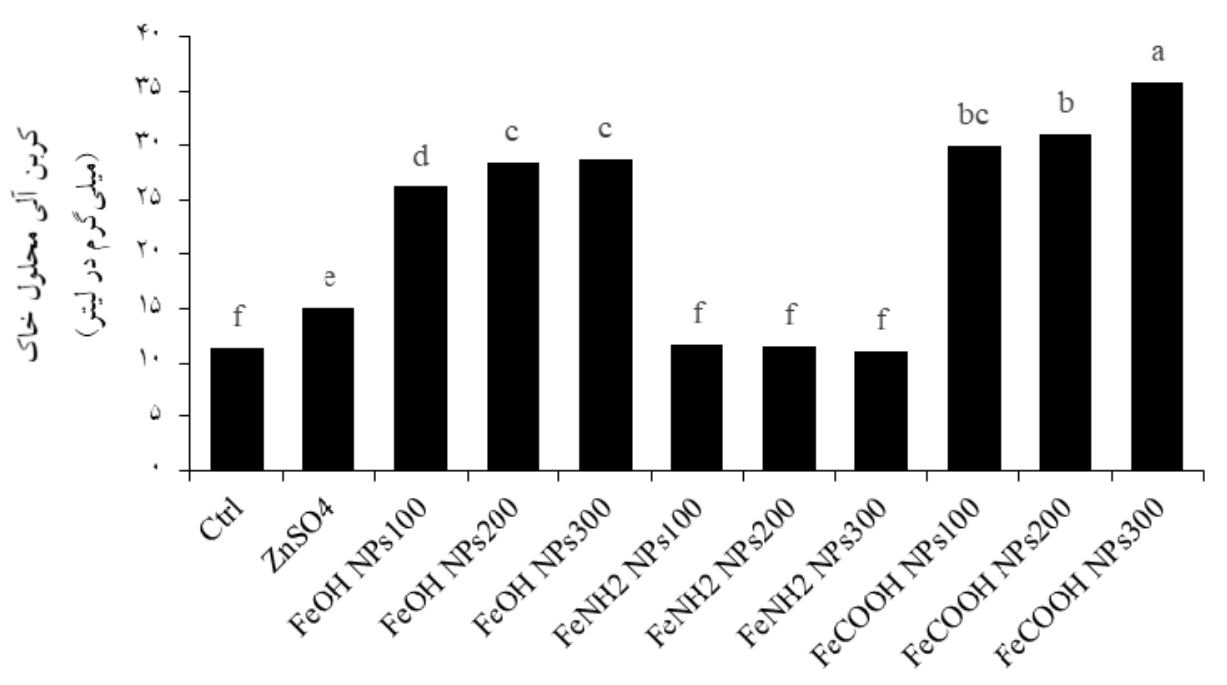

$$
\begin{aligned}
& \text { شكل ه. مقايسه ميانخين تأثير تيمارها بر كربن آلى محلول خاك } \\
& \text { (حروف مشترك بيانگر عدم معنىدارى بين تيمارها براساس آزمون توكى در سطح هـ است) }
\end{aligned}
$$

(Ctrl)

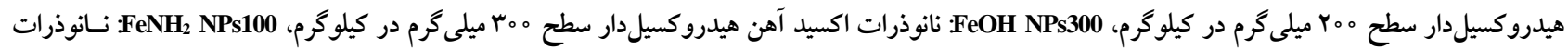

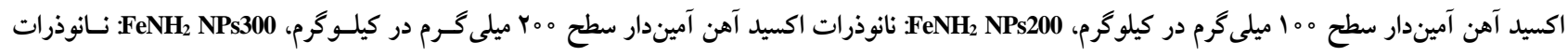

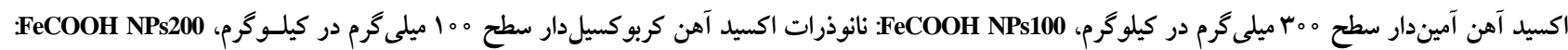

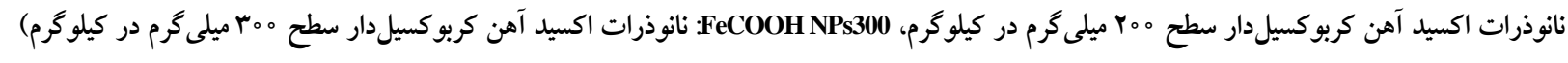

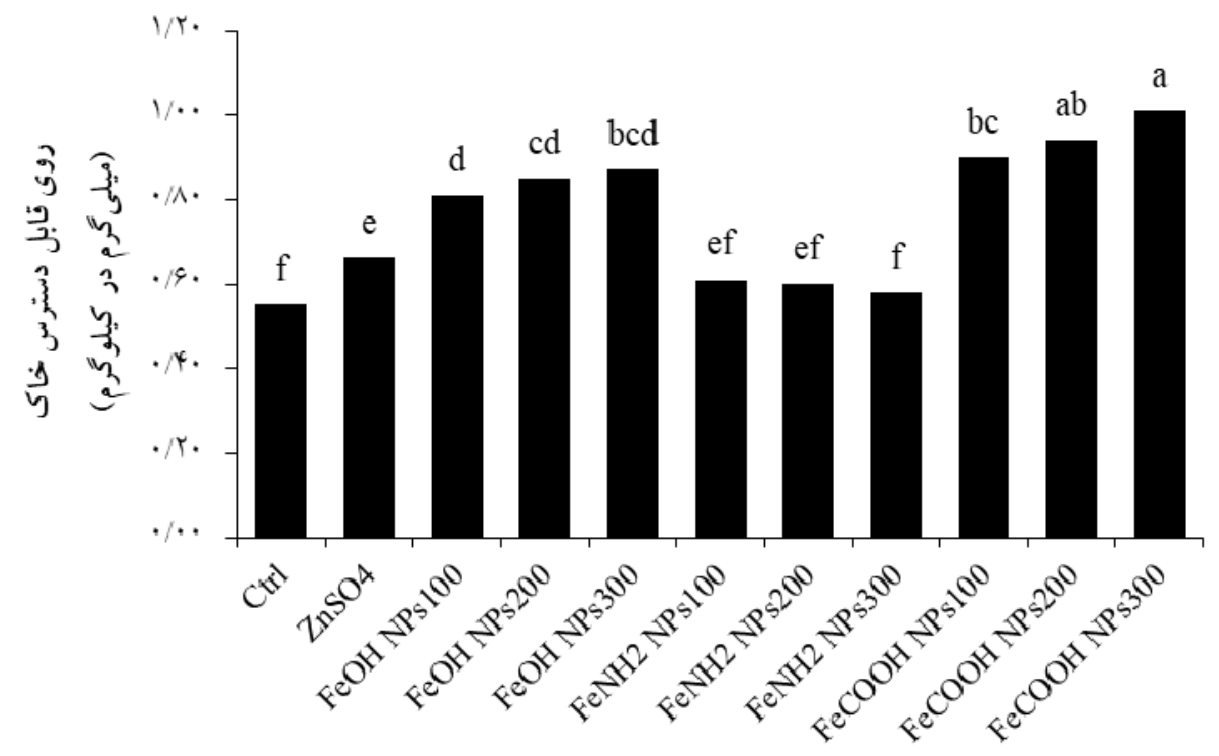

$$
\begin{aligned}
& \text { شكل צ. مقايسه ميانخين تأثير تيمارها بر روى قابل دسترس خاى }
\end{aligned}
$$

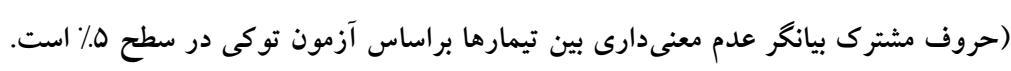

(Ctrl)

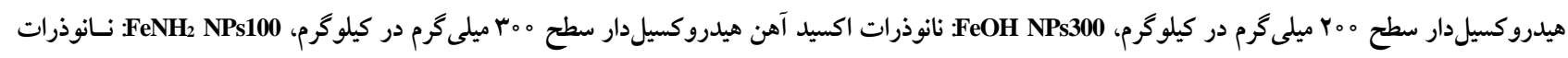

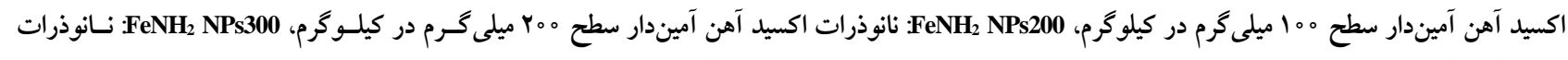
اكسيد آهن آميندار سطح ه مب ميلى

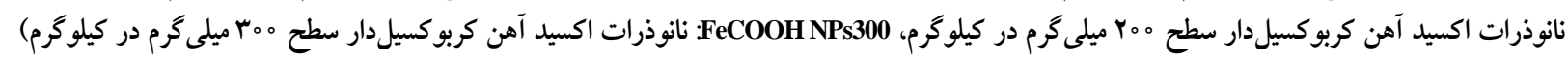


جدول r. تجزيه واريانس اثر تيمارها بر ب.هاش، كربن آلى محلول و روى قابل دسترس خاك

\begin{tabular}{|c|c|c|c|c|}
\hline \multicolumn{3}{|c|}{ ميانخين مربعات } & \multirow{2}{*}{ درجه آزادى } & \multirow{2}{*}{ منبع تغييرات } \\
\hline روى قابل دسترس خاك & كربن آلى محلول خاى & بِ.هاش خاك & & \\
\hline$\circ / \circ \wedge^{* * * *}$ & $r \Lambda \circ / \Pi^{\prime * * * * *}$ & $\circ / \circ Y^{* * * *}$ & 10 & تيمار \\
\hline $0 / 00004$ & $0 / 09$ & ०/००००/r & r & خطا \\
\hline $1 / 04$ & $1 / 1 \mu$ & $0 / 10$ & - & ضريب تغييرات \\
\hline
\end{tabular}

تأثير نانوذرات اكسيد آهن عاملدار و كود شيميايى سولفات روى بر غلظت گونههاى شيميايى غالب روى

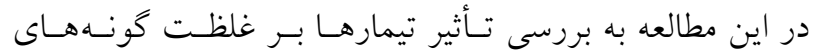

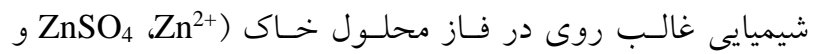

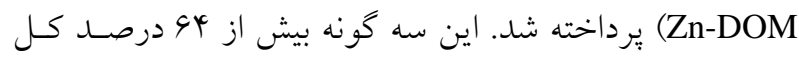
روى محلول را تشكيل دادند و غلظت ساير گونهها ناجيز بود.

\section{Zونه}

نتايج تجزيه واريانس نشان داد كه تأثير تيمارها بر غلظـت

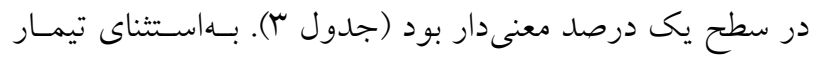

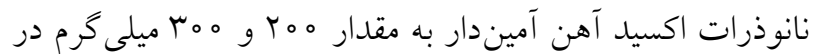

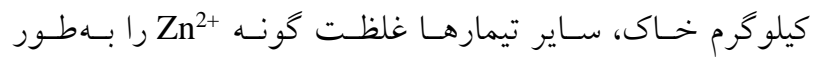

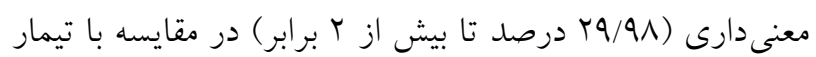
شاهد افزايش دادند (جدول Y) (Y).

$\mathrm{ZnSO}_{4}$

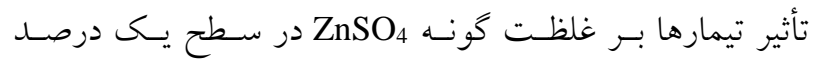

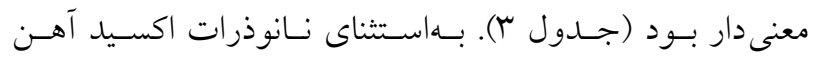

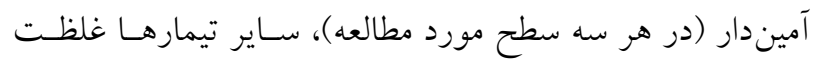

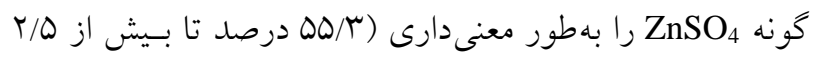
برابر) در مقايسه با تيمار شاهد افزايش دادند (جلدول بالث).

Zونه Zn-DOM نانوذرات اكسيد آهن عامل دار و كـود شـيميايى سـولفات روى
زوج الكترونهاى آزاد بوده و الكترونگاتيوى كمترى نسـبت بـهـ

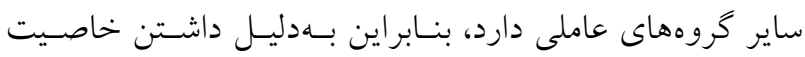

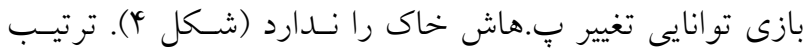

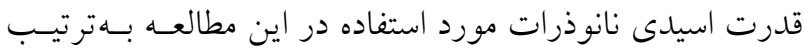

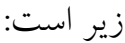

$\mathrm{Fe}_{3} \mathrm{O}_{4}-\mathrm{COOH}>\mathrm{Fe}_{3} \mathrm{O}_{4}-\mathrm{OH}>\mathrm{Fe}_{3} \mathrm{O}_{4}-\mathrm{NH}_{2}$

عـلاوه بــر ايـن، بــا تحريـك ريشــهـ توسـط نــانوذرات و

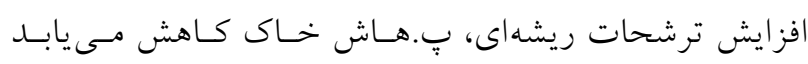

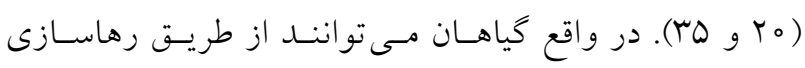

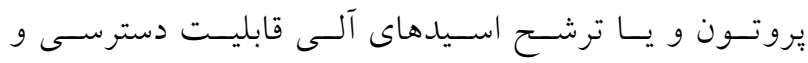
جذب عناصر مغذى كممصرف منطقه ريشه را افـزايش دهنـــ

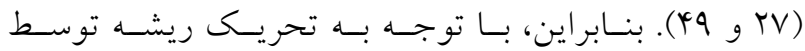
نانوذرات اكسيد آهن عامل دار و افزايش ترشحات ريشهاى و

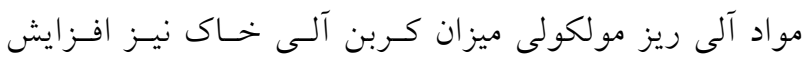

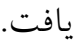
با آزادسازى يروتون (H) از كروههاى عاملى نسانوذرات

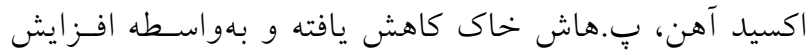

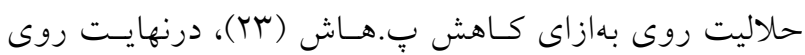
قابل دسترس خاك افزايش يافـت. عـلاوه بــر ايسن، افـزايش

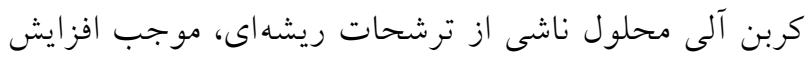

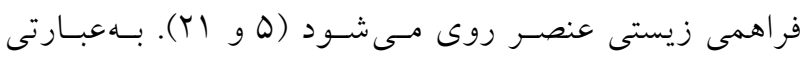

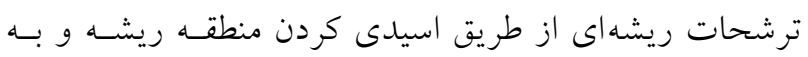

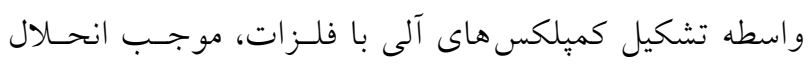

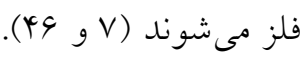


جدول r. تجزيه واريانس تأثير تيمارها بر غلظت گونهاى شيميايى غالب روى در فاز محلول خاك

\begin{tabular}{|c|c|c|c|c|}
\hline \multicolumn{3}{|c|}{ ميانكين مربعات } & \multirow{2}{*}{ درجه آزادى } & \multirow{2}{*}{ منبع تغييرات } \\
\hline Zn-DOM & $\mathrm{ZnSO}_{4}$ & $\mathrm{Zn}^{2+}$ & & \\
\hline $9 / V \times 10^{-19 \text { 絭䊅 }}$ & $T / \Gamma \times 10^{-10 * * \%}$ & $Y / \Delta \times 10^{-1 \mid Y_{* * * *}}$ & 10 & تيمار \\
\hline $1 / \lambda \times 10^{-11}$ & $1 / 1 \times 10^{-1 V}$ & $1 / T \times 10^{-19}$ & rr & خطا \\
\hline $9 / \mathrm{V}$ & $0 / 01$ & $Y / V T$ & - & ضريب تغييرات \\
\hline
\end{tabular}

جدول f. مقايسه ميانخين تأثير تيمارها بر غلظت گونههاى شيميايى غالب روى (Mol/L) در فاز محلول خاك

\begin{tabular}{|c|c|c|c|}
\hline Zn-DOM & $\mathrm{ZnSO} 4$ & $\mathrm{Zn} 2+$ & تيمار \\
\hline $4 / 9 \times 10^{-9 g}$ & $r / 9 \times 10^{-\wedge g}$ & $1 / \pi \times 10^{-v_{g}}$ & Ctrl \\
\hline $9 / 0 \times 10^{-9 f}$ & $y / 9 \times 10^{-\lambda_{f}}$ & $1 / \wedge \times 10^{-v_{e}}$ & $\mathrm{ZnSO}_{4}$ \\
\hline$r \times 1 \circ^{-\Lambda_{e}}$ & $9 \times 10^{-\Lambda_{e}}$ & $r / \mu_{X} \mid 0^{-v_{d}}$ & FeOH NPs100 \\
\hline$r / \Delta \times 10^{-\wedge d}$ & $V \times 10^{-\wedge \mathrm{de}}$ & $r / \Delta \times 10^{-v d}$ & FeOH NPs200 \\
\hline$r / 9 \times 10^{-\lambda_{c d}}$ & $V / 9 \times 10^{-\Lambda_{C d}}$ & $r / 9 \times 10^{-v_{C}}$ & FeOH NPs300 \\
\hline $9 \times 10^{-9 f}$ & $\Gamma / \Lambda \times 10^{-\wedge \mathrm{fg}}$ & $1 / 0 \times 10^{-v_{e f}}$ & $\mathrm{FeNH}_{2} \mathrm{NPs} 100$ \\
\hline $0 / \mu \times 10^{-9 g}$ & $\Gamma / \Delta \times 10^{-\wedge g}$ & $1 / 4 \times 10^{-v_{f g}}$ & $\mathrm{FeNH}_{2} \mathrm{NPs}_{200}$ \\
\hline $0 / 1 \times 10^{-9 g}$ & $r / \Psi \times 10^{-\wedge g}$ & $1 / \mu_{x} 0^{-v_{f g}}$ & $\mathrm{FeNH}_{2} \mathrm{NPs} 300$ \\
\hline$\Gamma / T \times 10^{-\lambda_{C}}$ & $\Lambda / 9 \times 1 \circ^{-\Lambda_{\mathrm{bc}}}$ & $r /|\times| 0^{-V_{b c}}$ & FeCOOH NPs100 \\
\hline$\Gamma / 9 \times 1 \circ^{-\lambda_{b}}$ & $9 / \Delta \times 10^{-\lambda_{b}}$ & $r / 4 \times 10^{-v_{b}}$ & FeCOOH NPs200 \\
\hline$Y / V \times 10^{-\lambda_{a}}$ & $1 / 1 \times 10^{-v_{a}}$ & $r / 9 \times 10^{-v_{a}}$ & FeCOOH NPs300 \\
\hline
\end{tabular}

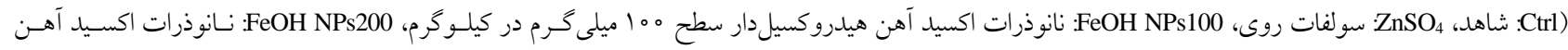

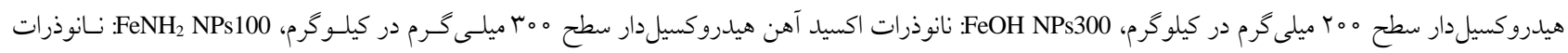

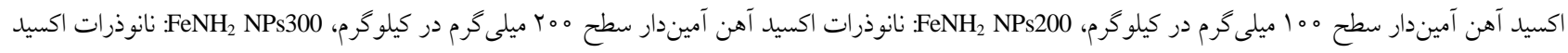

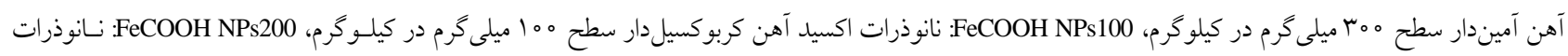

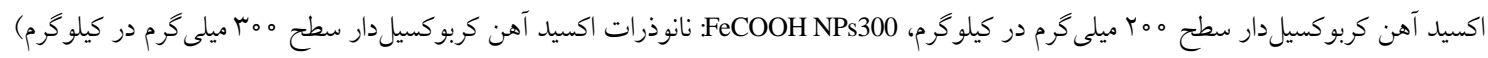

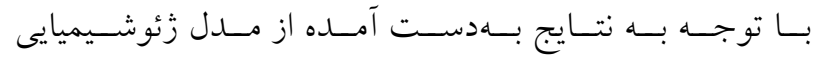

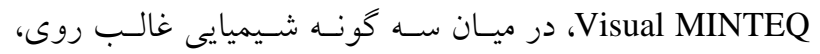

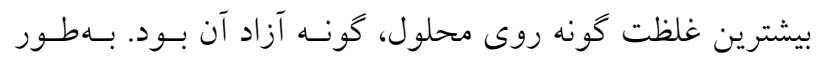

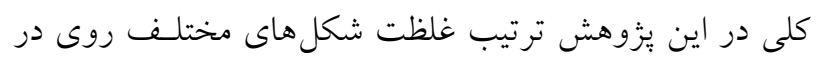

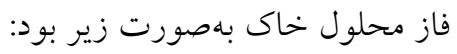
$\mathrm{Zn}^{2+}<\mathrm{ZnSO}_{4}<\mathrm{Zn}-\mathrm{DOM}$

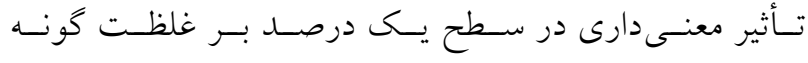
Zn-DOM داشتند (جدول r). بهاستثناى تيمار نانوذرات اكسيد

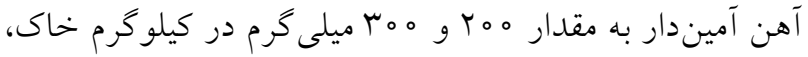

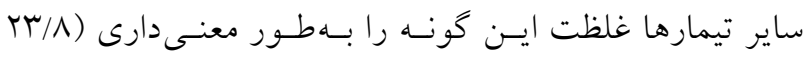

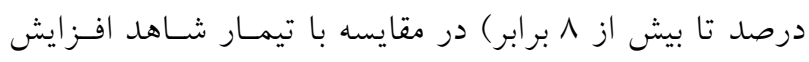

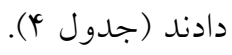


در مقايسه با تغييرات كونه روى كميلكس شده با تركيبات آلى

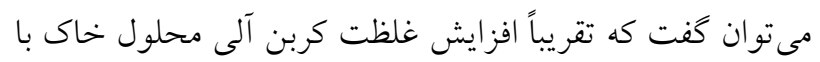
افزايش غلظت كونه روى كميلكس شده بات تركيبات آلى همـراه

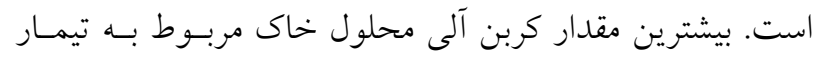

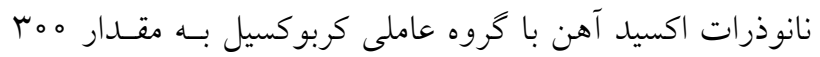

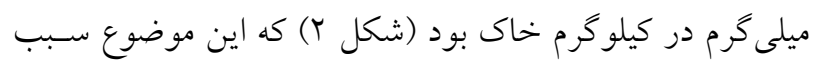

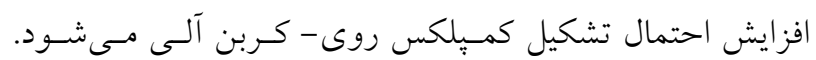

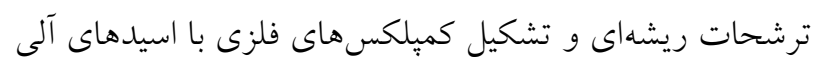

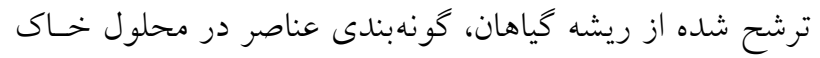

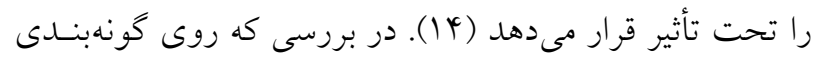

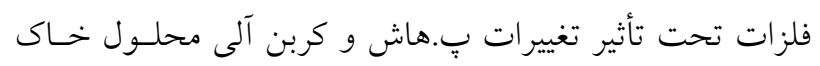

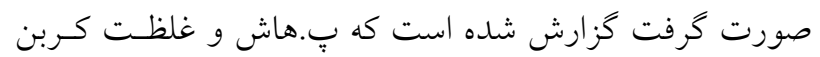

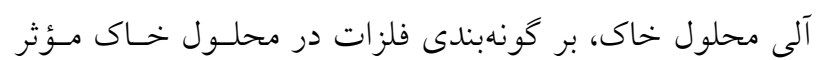

هستند (1) (1). (1)

\section{غلظت و جذب روى گياه گندم}

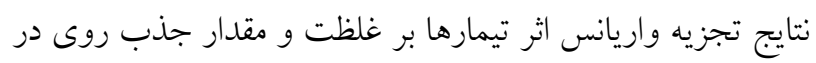

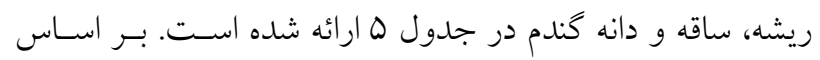

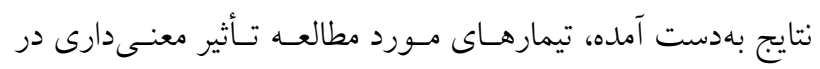
سطح يك درصد بر غلظت و جذب روى ريشه، ساقه و دانه گندم داشته است (جدول ه). تمامى تيمارها بهاستثناى نانوذرات اكسيد آهن آميندار (در هـر سه سطح مورد مطالعه) غلظت روى ريشـه را بـهـــور معنسى دارى

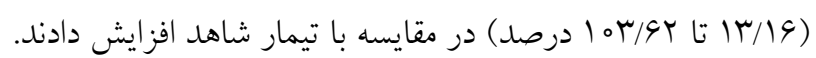
بهاستناى نانوذرات اكسيد آهن آميندار به مقدار همب ميلى گرم بـر

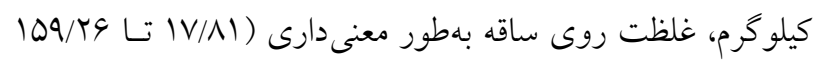
درصد) تحت تأثير نانوذرات اكسيد آهن عاملدار و كود شـيميايى سولفات روى در مقايسه با تيمار شاهل، افزايش يافت (جــدول 9). تمامى تيمارها بهاستثناى نانوذرات اكسيد آهن آميندار (بـه مقـدار

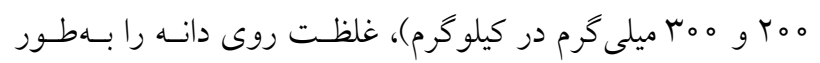

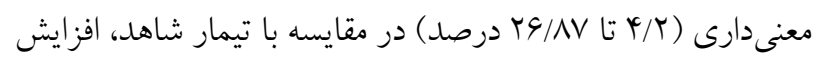
دادند (جدول (9).
براساس نتايج اين آزمايش، نانوذرات اكسيد آهن عامل دار باعث

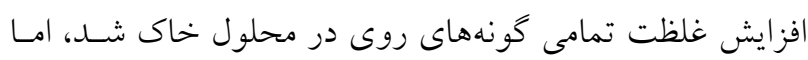

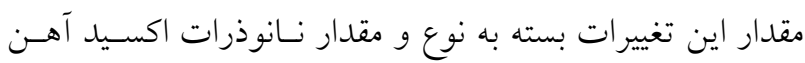

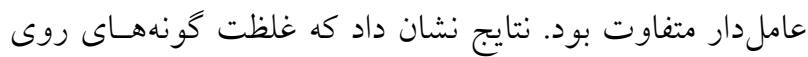

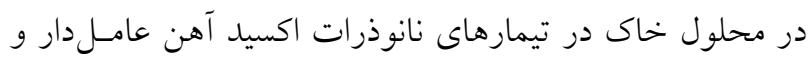

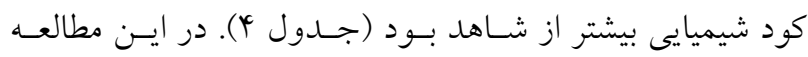

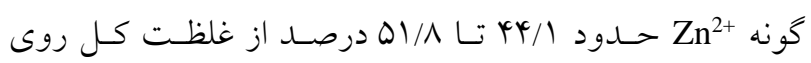
محلول را بهخود اختصاص داده است. برخى محققـان كـزارش

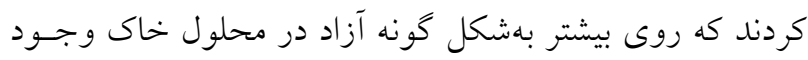

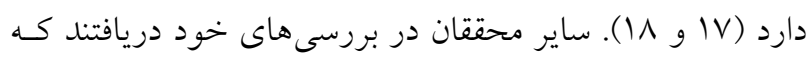

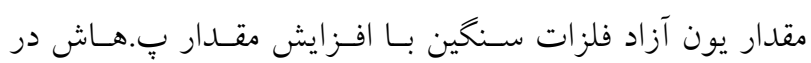
خاى رابطه معكوس داشته و با كاهش بِ.هاش كونـهـ آزاد فلـز

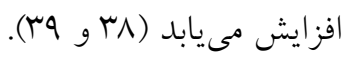

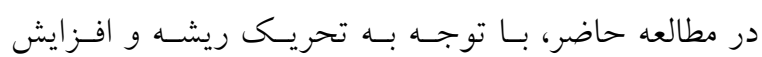

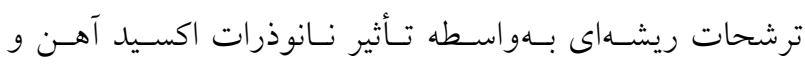
همجنين قدرت اسيدى گروههاى عاملى، مقدار ب.هـاش خـاى

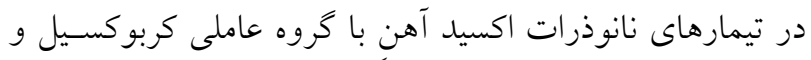

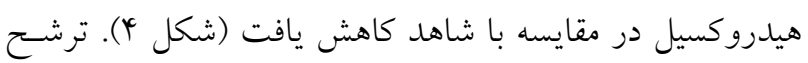

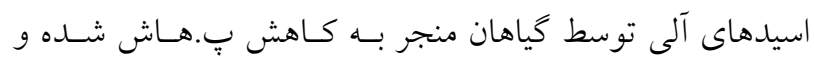

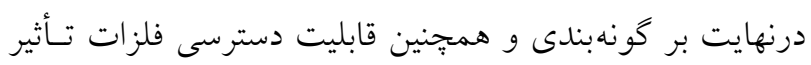

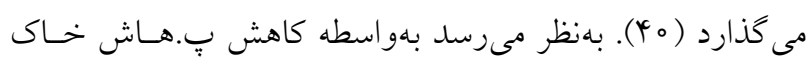

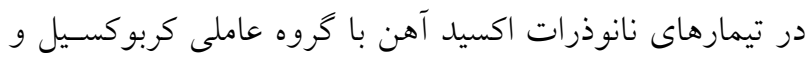

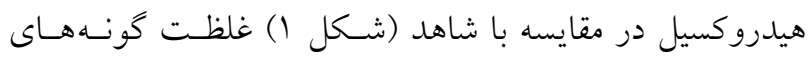

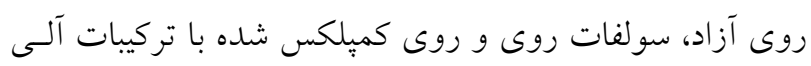

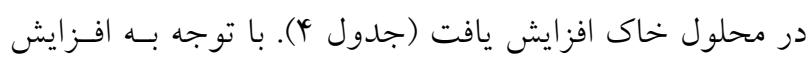

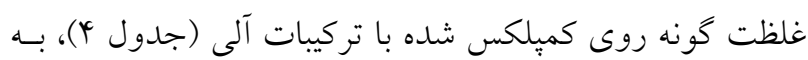
نظر مىرسد كه علاوه بر ب..هاش، ترشحات ريشهاى كَندم نيـز

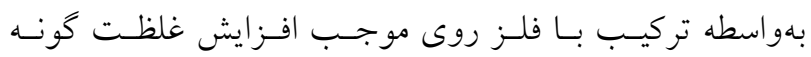

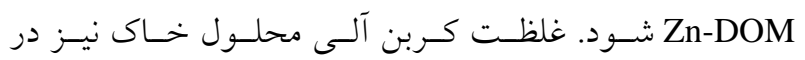

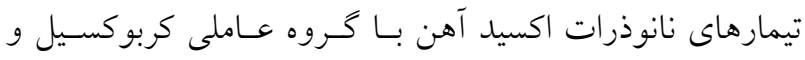
هيدروكسيل و كود شيميايى بهطور معنسى دارى بيشتر از شـاهد

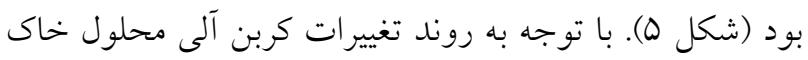




\begin{tabular}{|c|c|c|c|c|c|c|c|}
\hline \multirow[b]{2}{*}{ جذب دانه } & \multirow[b]{2}{*}{ جذب ساقه } & \multicolumn{2}{|c|}{ ميانخين مربعات } & \multirow[b]{2}{*}{ غلظت روى در ساقه } & \multirow[b]{2}{*}{ غلظت روى در ريشه } & \multirow{3}{*}{ آزادى درجه } & \multirow[b]{2}{*}{ تغييرات } \\
\hline & & جذب ريشه & غلظت روى در دانه & & & & \\
\hline & (ميلى گرم بر كلدان) & & & (ميلى گرم بر كيلوكرم) & & & \\
\hline $.04 \& Y \Delta \wedge 90^{* *}$ & 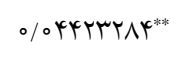 & $\% 100019999^{* * *}$ & $100 /\left.D Y Y \Delta G\right|^{* *}$ & 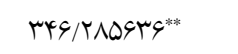 & IYIMVYVKY** & 10 & تيمار \\
\hline ०/O०OMVYT. & \%००M49901 & $\circ / 000000 \wedge r$ & ०/T\&VA. & $0 / Y 01010$ &.$/ 1909.9$ & Tr & خطا \\
\hline T/GYTOVI & $F / 11 \wedge V<q$ & F/OITEVI & -NAYQVN & I/OTYTLD & INATIGY & - & ضغريب \\
\hline
\end{tabular}

جدول 9. مقايسه ميانخين اثر تيمارها بر غلظت و جذب روى در گندم

\begin{tabular}{|c|c|c|c|c|c|c|}
\hline (مذب دانه & 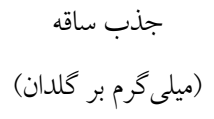 & (مذب ريشرم بر گلدان) & غلظت روى در دانه & غلظت روى در ساقه & غلظت روى در ريشه & تيمار \\
\hline 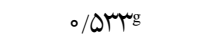 & -/lQYe & $0 / 01 \mu q^{f}$ & $\Delta Q / 4 r f g$ & $1 \mathrm{~V} / 09^{\mathrm{g}}$ & $10 / N r^{\mathrm{g}}$ & Ctrl \\
\hline $0 / 91 Q^{f}$ & $0 / 19^{d}$ & o/olvpe & $91 / 9 \mu^{\mathrm{e}}$ & $r \circ / T^{f}$ & $I V / \Lambda^{f}$ & $\mathrm{ZnSO}_{4}$ \\
\hline$\circ / V \circ Y^{e}$ & - $/ Y Q^{C}$ & o/orked & $94 / \Gamma \Delta^{\mathrm{d}}$ & m/re & $r r / q^{e}$ & $\begin{array}{c}\mathrm{FeOH} \\
\text { NPs100 }\end{array}$ \\
\hline$\circ / V \wedge \varphi^{d}$ & $\circ / N I^{b}$ & $\%$ $\% \Lambda_{\Lambda}^{\text {cd }}$ & $9 N / 9 Q^{C}$ & $r \Delta / \varphi^{\mu d}$ & $r \Delta / N Q^{d}$ & $\begin{array}{c}\mathrm{FeOH} \\
\text { NPs200 }\end{array}$ \\
\hline$\circ / \Lambda \circ Y^{\mathrm{cd}}$ & 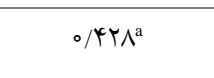 & $\circ / \circ \mu_{\circ} q_{a b}$ & $99 / 10^{c}$ & MN/TGc & $r \varepsilon /\left.\Delta\right|^{\mathrm{d}}$ & $\begin{array}{c}\mathrm{FeOH} \\
\text { NPs300 }\end{array}$ \\
\hline$\circ / 91 \wedge^{f}$ & $0 / / 9 Y^{d}$ & $\% / 010 Q^{e f}$ & $9 \circ / 90^{e}$ & $19 / \Lambda \mu^{f}$ & $19 / \mathrm{Ng}^{\mathrm{g}}$ & $\begin{array}{c}\mathrm{FeNH}_{2} \\
\mathrm{NPs} 100\end{array}$ \\
\hline $0 / 99 \mathrm{~V}^{\text {ef }}$ & - / $\wedge \Phi^{\mathrm{de}}$ & $0 / 0 \mid \psi \Lambda^{f}$ & $\varphi \circ / V Q^{\mathrm{ef}}$ & $|N / q|^{f f}$ & $19 / \mathrm{rg}^{\mathrm{g}}$ & $\begin{array}{c}\mathrm{FeNH}_{2} \\
\text { NPs200 }\end{array}$ \\
\hline $0 / 90 Q^{e f}$ & o/IVYde & $0 / 0 \mid k \mu^{f}$ & $\Delta q / 198$ & IV/RGg & $10 / \wedge 9^{\circ}$ & $\begin{array}{c}\mathrm{FeNH}_{2} \\
\mathrm{NPs} 300\end{array}$ \\
\hline$\circ / \Lambda$ fabc & $\circ / W^{b}$ & \%OYVIC & $V \backslash / 1 q^{b}$ & $r V / \mu^{c c}$ & $r \Lambda / \Lambda \mu^{c}$ & $\begin{array}{c}\text { FeCOOH } \\
\text { NPs100 }\end{array}$ \\
\hline$\circ / A V^{\text {ab }}$ & $\circ / 4 r \Delta^{a}$ & $\circ /\left.\circ \uparrow q\right|^{b c}$ & $V Y / q^{b}$ & FT/Mrb & $\mu_{0} / 4 I^{b}$ & $\begin{array}{c}\mathrm{FeCOOH} \\
\text { NPs200 }\end{array}$ \\
\hline - /9rya & $\circ / 4 \Delta q^{a}$ & ס & $V Q / \uparrow^{a}$ & $\mu \varphi / \mu^{a}$ & $r Y /{ }^{\prime} r^{a}$ & $\begin{array}{c}\text { FeCOOH } \\
\text { NPs300 }\end{array}$ \\
\hline
\end{tabular}

حروف مشترك بيانكر عدم معنىدارى بين تيمارها بر اساس آزمون توكى در سطح ها هستند. ( Ctrl: شاهد، ZnSO

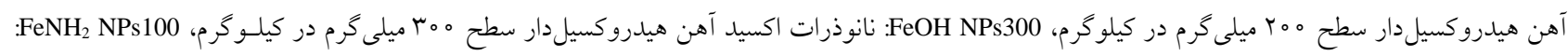

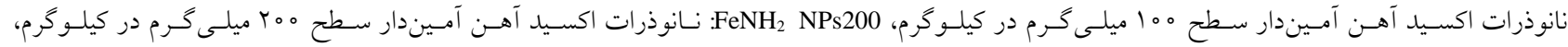

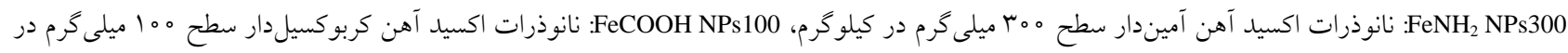

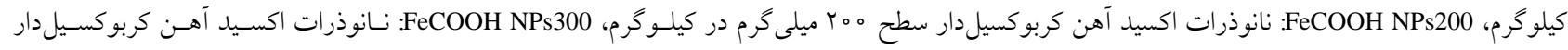
سطح مبام ميلى گرم در كيلوكرم) 
جدول V. ضرايب همبستخى بين غلظت گونههاى غالب روى در فاز محلول خاك با روى قابل دسترس خاك، غلظت و جذب روى در گندم

\begin{tabular}{|c|c|c|c|c|c|c|c|}
\hline جذب روى دانه & جذب روى & جذب روى ريشه & غلظت روى & غلظت روى & غلظت روى ريشه & دسترس خابل & \\
\hline$\circ / Y^{* * *}$ & $\circ / V^{* *}$ & $\circ / \vee q^{* *}$ & $\circ / \wedge D^{* *}$ & $\circ / \wedge \varphi^{* *}$ & $\circ / \Lambda^{* *}$ & $0 / 99^{* *}$ & $\mathrm{Zn}^{2+}$ \\
\hline $0 / 9 \Lambda^{* *}$ & $\circ N r^{* *}$ & $\circ /\left.\Lambda\right|^{* *}$ & $\circ / \wedge \mu^{* * *}$ & $\circ / \Lambda r^{* *}$ & $\circ / \wedge Q^{* *}$ & $\circ / 9 \mu^{* * *}$ & Zn-DOM \\
\hline ns & ns & ns & ns & ns & ns & $\circ / V^{* *}$ & $\mathrm{ZnSO}_{4}$ \\
\hline
\end{tabular}

"ns به ترتيب معنى دارى در سطح احتمال ا درصد و عدم معنىدارى

نتايج همبستخى بين شكلهاى شيميايى مختلف روى در فـاز

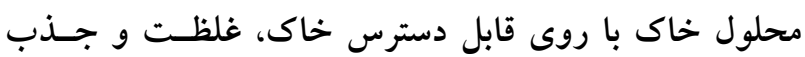
روى در گندم

نتايج همبستكى بـين كونسهــاى شسيميايى غالـب روى در فـاز

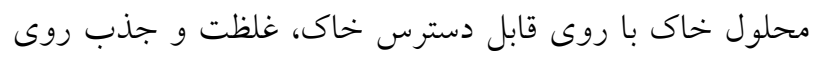

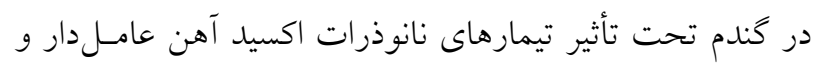
كود شيميايى سولفات روى در جدول هه نشان داده شده اسـت.

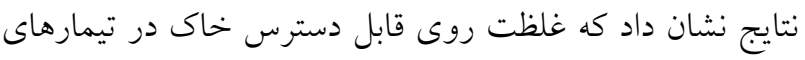

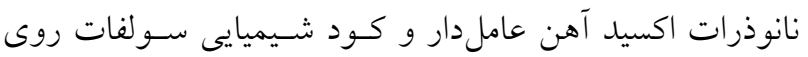

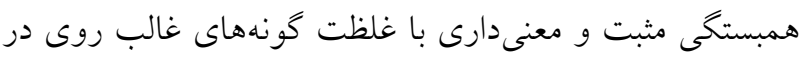
محلول خاك داشت (جدول ه). همجينين مشاهده شد كـه بـين

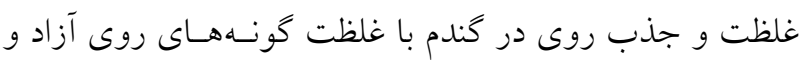

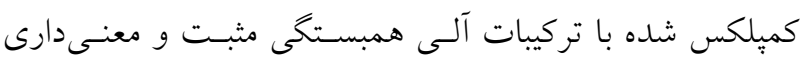

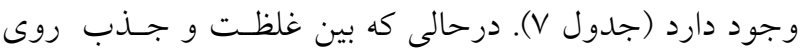

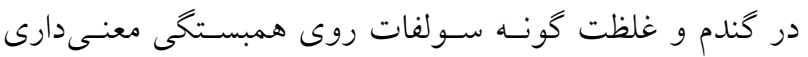

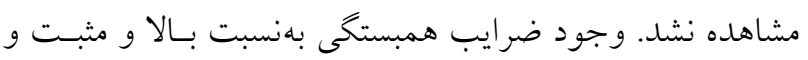

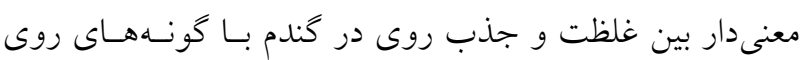

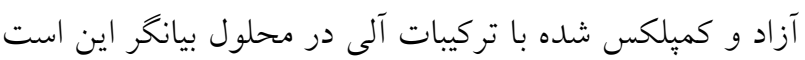

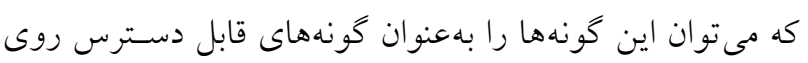

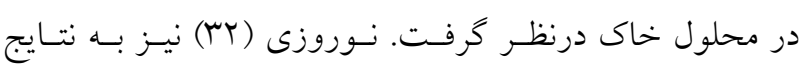
مشابهى دست يافت.

\section{نتيجه گيرى}

نتايج اين آزمايش نشان داد كه كـاربرد نـانوذرات اكسـيد آهـن

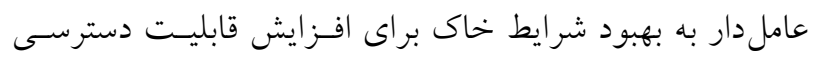

نانوذرات اكسيد آهن كربو كسيل دار به مقدار همب ميلى گرم در

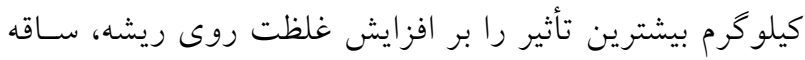

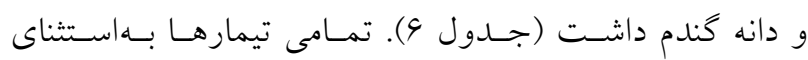
نانوذرات اكسيد آهن آميندار (در هر سه سطح مورد مطالعه)،

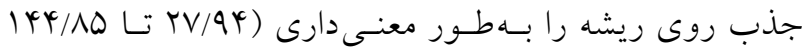
درصد) در مقايسه با تيمار شاهد افـزايش دادنـــ (جــول 9). بيشترين و كمترين ميزان جذب روى در سـاقه، بـهـترتيـب در

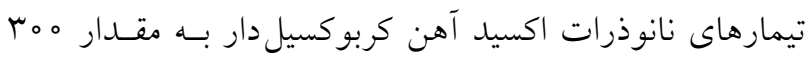

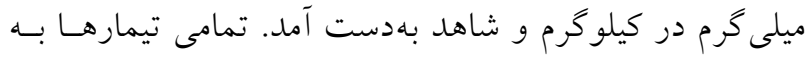

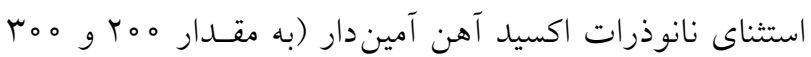

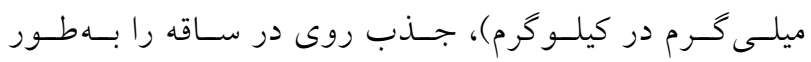

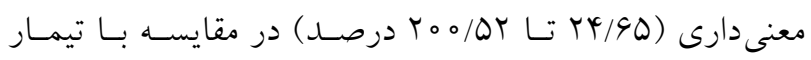

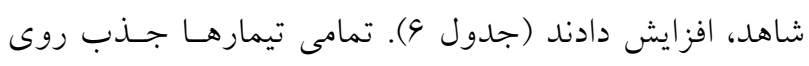
دانه را بهطور معنى دارى ( با تيمار شاهد افزايش دادند (جدول 9). بيشترين ميزان جذانب

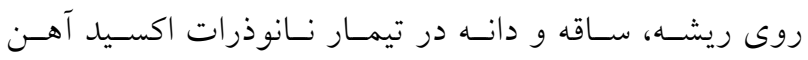

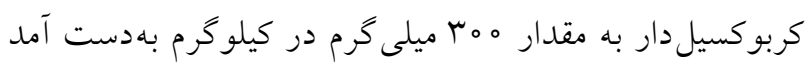

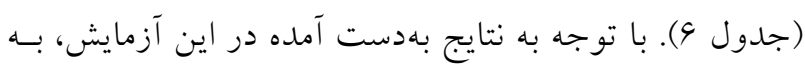
واسطه تأثير معنى دارى كه تيمارهاى آزمايش (بهاستثناى تيمار

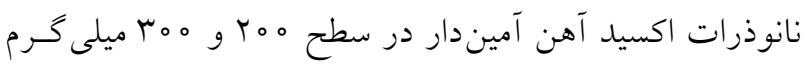
بر كيلو گرم) بر كاهش ب.هاش خاك داشتند، ميزان روى قابل دسترس خاك افزايش يافت و درنتيجه، غلظت و جـــب روى

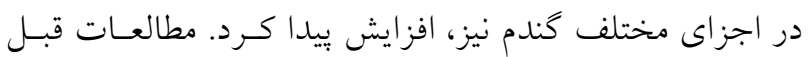

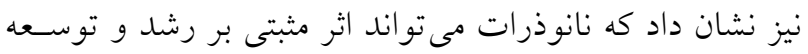

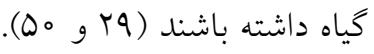




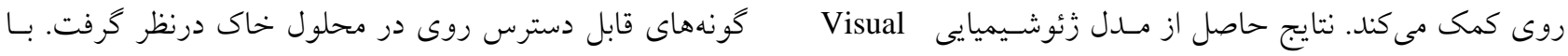

$$
\begin{aligned}
& \text { MINTEQ نشان داد كه بيشترين مقدار كونه آزاد روى در تيمار اينحال با توجه به بحـث سـلامت محسيط زيسـت و همجنـين }
\end{aligned}
$$

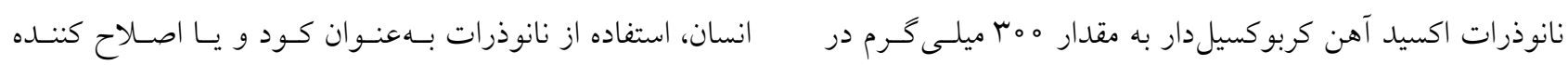

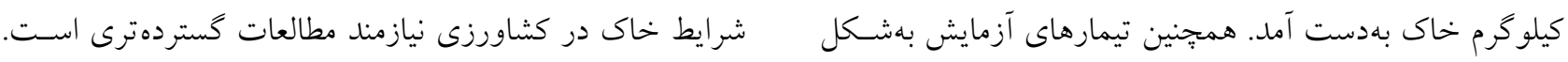

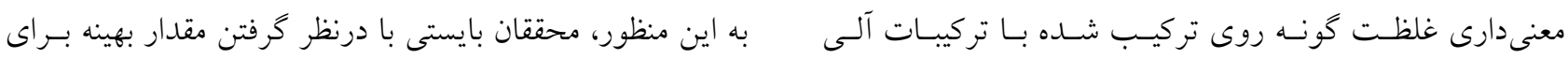

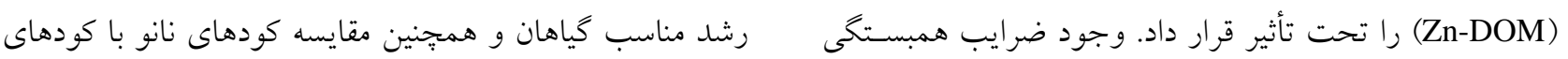

$$
\begin{aligned}
& \text { بهنست بالا و مثبت و معنى دار بـين غلظـت و جـذبـ روى در موجود و ساير استراتزىهاى مـورد اسـتفاده در كشـاورزى، بـه } \\
& \text { كندم با كونهاى روى آزاد و كميلكس شده با تركيبات آلى در بروسى هاى بيشترى درباره مزايا و معايب تركيـات و كودهـاى }
\end{aligned}
$$

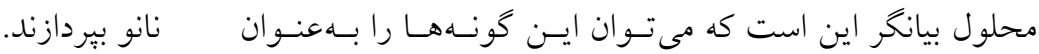

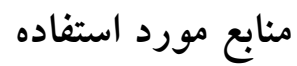

1. Abdollahi, A., M. Norouzi Masir, M. Taghavi Zahedkolaei and A. A. Moezzi. 2018. The effectiveness of synthesized $\mathrm{ZnO}$ nanoparticles on $\mathrm{Zn}$ uptake and some growth indices of wheat. Journal of Soil Management and Sustainable Production 8(1): 125-141.

2. Alloway, B. J. 2009. Soil factors associated with zinc deficiency in crops and humans. Journal of Environmental Geochemistry and Health 31(5): 537-548.

3. Atafar, Z., A. Mesdaghinia, J. Nouri, M. Homaee, M. Yunesian, M. Ahmadimoghaddam and A. H. Mahvi. 2010. Effect of fertilizer application on soil heavy metal concentration. Environmental Monitoring and Assessment 160(14): 83-89.

4. Backes, C. A., R. G. McLaren, A. W. Rate and R. S. Swift. 1995. Kinetics of cadmium and cobalt desorption from iron and manganese oxides. Soil Science Society of America Journal 59(3): 778-785.

5. Bais, H. P., T. L. Weir, L. G. Perry, S. Gilroy and J. M. Vivanco. 2006. The role of root exudates in rhizosphere interactions with plants and other organisms. Annual Review of Plant Biology 57: 233-266.

6. Catlett, K. M., D. M. Heil, W. L. Lindsay and M. H. Ebinger. 2002. Soil chemical properties controlling zinc ${ }^{2+}$ activity in 18 Colorado soils. Soil Science Society of America Journal 66(4): 1182-1189.

7. Chen, W., A. C. Chang, L. Wu, A. Page and B. Koo. 2010. Trace elements in biosolidsamended soils. PP. 313-336. In: Hooda, P. S. (Eds.), Trace Elements in Soils, First ed. Blackwell Publishing Ltd.

8. Chen, Z., Z. Geng, Z. Zhang, L. Ren, T. Tao, R. Yang and Z. Guo. 2014. Synthesis of magnetic $\mathrm{Fe}_{3} \mathrm{O}_{4} \mathrm{C}$ nanoparticles modified with $-\mathrm{SO}_{3} \mathrm{H}$ and $-\mathrm{COOH}$ groups for fast removal of $\mathrm{Pb}^{2+}, \mathrm{Hg}^{2+}$, and $\mathrm{Cd}^{2+}$ ions. European Journal of Solid State and Inorganic Chemistry 2014(20): 3172-3177.

9. De Valença, A. W., A. Bake, I. D. Brouwer and K. E. Giller. 2017. Agronomic biofortification of crops to fight hidden hunger in sub-Saharan Africa. Global Food Security 12: 8-14.

10. Gee, G. W. and J. W. Bauder. 1986. Particle size analysis. PP: 383-411. In: Klute, A. (Ed.), Methods of Soil Analysis. Part 1. American Society of Agronomy, Madison, WI, USA.

11. Ghormade, V., M. V. Deshpand and K. M. Paknikar. 2011. Perspectives for nano-biotechnology enabled protection and nutrition of plants. Biotechnology Advances 29(6): 792-803.

12. Gupta, P. K. 2004. Soil, Plant, Water and Fertilizer Analysis. First Ed. Agrobios (India).

13. Harter, R. D and R. Naidu. 1995. Role of metal-organic complexation in metal sorption by soils. Advances in Agronomy 55: 219-263.

14. Hinsinger, P. 2001. Bioavailability of trace elements as related to root-induced chemical changes in the rhizosphere. PP: 25-41. In: Hooda, P.S. (Eds.), Trace Elements in Soils. John Wiley and Sons, Publication, CRC Press, United States.

15. Huang, S. W. and J. Y. Jin. 2008. Status of heavy metals in agricultural soils as affected by different patterns of land use. Environmental Monitoring and Assessment 139(1-3): 317-327.

16. Jones, D. L. 1998. Organic acids in the rhizosphere. A critical review. Plant and Soil 205: 25-44.

17. Kalis, E. J., E. J. Temminghoff, A. Visser and W. H. Van Riemsdijk. 2007. Metal uptake by Lolium perenne in contaminated soils using a four-step approach. Environmental Toxicology and Chemistry 26(2): 335-345. 
18. Khoshgoftarmanesh, A. H., H. Shariatmadari, N. Karimian, M. Kalbasi and S. E. A. T. M. Van der Zee. 2006. Cadmium and zinc in saline soil solutions and their concentrations in wheat. Soil Science Society of America Journal 70(2): 582-589.

19. Khoshgoftarmanesh, A. H., M. Afyuni, M. Norouzi, S. Ghiasi and R. Schulin. 2018. Fractionation and bioavailability of zinc ( $\mathrm{Zn})$ in the rhizosphere of two wheat cultivars with different $\mathrm{Zn}$ deficiency tolerance. Geoderma 309: 1-6.

20. Kurepa, J., T. Paunesku, S. Vogt, H. Arora, B. M. Rabatic, J. Lu and J. A. Smalle. 2010. Uptake and distribution of ultrasmall anatase $\mathrm{TiO}_{2}$ Alizarin red S nanoconjugates in Arabidopsis thaliana. Nano Letters 10(7): 2296-2302.

21. Li, H., J. Shen, F. Zhang, M. Clairotte, J. J. Drevon, E. Le Cadre and P. Hinsinger. 2008. Dynamics of phosphorus fractions in the rhizosphere of common bean (Phaseolus vulgaris L.) and durum wheat (Triticum turgidum durum L.) grown in monocropping and intercropping systems. Plant and Soil 312(1-2): 139-150.

22. Li, J., Y. Lu, H. Shim, X. Deng, J. Lian, Z. Jia and J. Li. 2010. Use of the BCR sequential extraction procedure for the study of metal availability to plants. Journal of Environmental Monitoring 12(2): 466-471.

23. Lindsay, W. L. 1979. Chemical equilibria in soils. First Ed. John Wiley and Sons Limited.

24. Lindsay, W. L. and W. A. Norvell. 1978. Development of a DTPA soil test for zinc, iron, manganese, and copper1. Soil Science Society of America Journal 42(3): 421-428.

25. Lindsay, W. L. 1991. Inorganic equilibria affecting micronutrients in soils. PP. 90-112. In: Mortvedt, J. J., F. R. Cox, L. M. Shuman and R. M. Welch. (Eds.), Micronutrients in Agriculture. Soil Science Society of America, Madison, WI.

26. Malakuti. M. J. and M. N. Gheibi. 1379. Determining Critical Limit of Effective Nutrients in Soil, Plants and Fruits to Increase the Quantitative and Qualitative Performance of Country Strategic Products. Second edition, Jihad-e Keshavarzi Publications, Karaj.

27. Marschner, H. 2012. Marschner's Mineral Nutrition of Higher Plants. Third Ed., Academic Press.

28. Moghaddasi, S., A. Fotovat, A. H. Khoshgoftarmanesh, F. Karimzadeh, H. R Khazaei and R. Khorassani. 2017. Bioavailability of coated and uncoated $\mathrm{ZnO}$ nanoparticles to cucumber in soil with or without organic matter. Ecotoxicology and Environmental Safety 144: 543-551.

29. Moghadam, A., H. Vattani, N. Baghaei and N. Keshavarz. 2012. Effect of different levels of fertilizer nano_iron chelates on growth and yield characteristics of two varieties of spinach (Spinacia oleracea L.): Varamin 88 and Viroflay. Research Journal of Applied Sciences, Engineering and Technology 4(22): 4813-4818.

30. Monreal, C. M., M. DeRosa, S. C. Mallubhotla, P. S. Bindraban and C. Dimkpa. 2015. Nanotechnologies for increasing the crop use efficiency of fertilizer-micronutrients. Biology and Fertility of Soils 52(3): 423-437.

31. Mortvedt, J. J. 1985. Plant uptake of heavy metals in zinc fertilizers made from industrial by-products. Journal of Environmental Quality 14(3): 424-427.

32. Norouzi Masir, M. 1393. Effects of cultivation history, plant residues, organic and chemical fertilizers and rubber waste on chemical fractions of zinc and its uptake in wheat in a calcareous soil. Ph.D Thesis of Soil Science, Faculty of Agriculture, Isfahan University of Technology.

33. Olsen, S. R., L. E. Sommers and A. L. Page. 1982. Chemical and microbiological properties of Phosphorus. PP: 403-430. In: Norman, A. G. (Eds.). Methods of Soil Analysis. Part 2. Association of Social Anthropologists Monograph, Academic Press, United States.

34. Parker, D. R., W. A. Norvell and R. L. Chaney. 1995. GEOCHEM-PC-A Chemical speciation program for IBM and compatible personal computers. PP. 253-269. In: Loeppert, R. H., A. P. Schwab and S. Goldberg. (Eds.), Chemical Equilibrium and Reaction Models, SSSA Spec. Publ. 42. SSSA and ASA, Madison, WI.

35. Peralta-Videa, J. R., J. A. Hernandez-Viezcas, L. Zhao, B. C. Diaz, Y. Ge, J. H. Priester, P. Ann Holden and J. L. Gardea-Torresdey. 2014. Cerium dioxide and zinc oxide nanoparticles alter the nutritional value of soil cultivated soybean plants. Plant Physiology and Biochemistry 80: 128-135.

36. Rao, C. R. M., A. Sahuquillo and J. F. Lopez-Sanchez. 2010. Comparison of single and sequential extraction procedures for the study of rare earth elements remobilisation in different types of soils. Analytica Chimica Acta 662 (2): 128-136.

37. Rhoades, J. D. 1996. Salinity: Electrical conductivity and total dissolved soils. PP: 417-435. In D. L. Sparks (Eds.), Methods of Soil Analysis. Part 3. Soil Science Society of America, Madison, WI.

38. Shahid, M., C. Dumat, M. Aslam and E. Pinelli. 2012. Assessment of lead speciation by organic ligands using speciation models. Chemical Speciation and Bioavailability 24(4): 248-252.

39. Tahervand, S. and M. Jalali. 2016. Sorption, desorption, and speciation of Cd, Ni, and Fe by four calcareous soils as affected by pH. Environmental Monitoring and Assessment 188(6): 322.

40. Tao, S., Y. J. Chen, F. L. Xu, J. Cao and B. G. Li. 2003. Changes of copper speciation in maize rhizosphere soil. Environmental Pollution 122(3): 447-454. 
41. Tulchinsky, T. H. 2010. Micronutrient deficiency conditions: global health issues. Public Health Reviews 32(1): 243-255.

42. Vanlauwe, B., K. Descheemaeker, K. E. Giller, J. Huising, R. Merckx, G. Nziguheba and S. Zingore. 2015. Integrated soil fertility management in sub-Saharan Africa: unravelling local adaptation. Soil Discussions 1(1): 491508.

43. Voortman, R. and P. S. Bindraban. 2015. Beyond N and P: Toward a land resource ecology perspective and impactful fertilizer interventions in sub-Saharan Africa. VFRC Report 2015/1. Virtual Fertilizer Research Center, Washington, DC.

44. Walkey, A. and A. I. Black. 1934. Examination of the degtjareff method for determining soil organic matter and organic matter and a proposed modification of the chromic and titration method. Soil Science 34: 29-38.

45. Wang Y. X. A. and H. Oyaizu. 2009. Evaluation of the phytoremediation potential of four plant species for dibenzofu-ran-contaminated soil. Journal of Hazardous Materials 168: 760-764.

46. Wang, J., C. B. Zhang and Z. X. Jin. 2009. The distribution and phytoavailability of heavy metal fractions in rhizosphere soils of Paulowniu fortunei (seem) Hems near a Pb/Zn smelter in Guangdong, PR China. Geoderma 148(3-4): 299-306.

47. WHO. 2016. Vitamin and Mineral Nutrition Information System. World Health Organization.

48. Zahra, Z., M. Arshad, R. Rafique, A. Mahmood, A. Habib, I. A. Qazi and S. A. Khan. 2015. Metallic nanoparticle $\left(\mathrm{TiO}_{2}\right.$ and $\left.\mathrm{Fe}_{3} \mathrm{O}_{4}\right)$ application modifies rhizosphere phosphorus availability and uptake by Lactuca sativa. Journal of Agricultural and Food Chemistry 63(31): 6876-6882.

49. Zhang, F., J. Shen, J. Zhang, Y. Zuo, L. Li and X. Chen. 2010. Rhizosphere processes and management for improving nutrient use efficiency and crop productivity: implications for China. Advances in Agronomy 107: 1-32.

50. Zhu, H., J. Q. Han and Y. Jin. 2008. Uptake, translocation, accumulation of manufactured iron oxide nanoparticles by pumpkin plants. Journal of Environmental Monitoring 10: 713-717. 


\title{
Effect of Functionalized Iron Oxide Nanoparticles and Zinc Sulfate Chemical Fertilizer on Zinc Speciation in Soil and Uptake of Zinc in Wheat
}

\author{
A. Abdolahi ${ }^{1}$, M. Norouzi Masir ${ }^{1 *}$, M. Taghavi ${ }^{2}$ and A. Moezzi ${ }^{1}$
}

(Received: July 28-2018; Accepted: September 30-2019)

\begin{abstract}
Nowadays, one of the ways to confront with the micronutrients deficiency is application of Nano materials to increase the availability of elements such as zinc for plants. Therefore, this study was conducted to investigate the effect of functionalized iron oxide nanoparticles and zinc sulfate chemical fertilizer on the zinc chemical forms in soil solution phase and its correlation with zinc concentrations and uptake in wheat. This study was carried out in a completely randomized design with three replications. Treatment consisted of functionalized iron oxide nanoparticles of Hydroxyl $(\mathrm{OH})$, Carboxyl $(\mathrm{COOH})$ and Amine $\left(\mathrm{NH}_{2}\right)$, each at three levels $\left(100,200\right.$ and $\left.300 \mathrm{mg}^{\mathrm{kg}} \mathrm{kg}^{-1}\right), \mathrm{ZnSO}_{4}\left(40 \mathrm{~kg} \cdot \mathrm{ha}^{-1}\right)$ and Control (without using iron oxide nanoparticles). At the end of the cultivation period, soil chemical properties such as $\mathrm{pH}$, soil available zinc and dissolved organic carbon and concentrations and the uptake of zinc in plant were measured. The results showed that $\mathrm{pH}$, available zinc and dissolved organic carbon content of soil solution were significantly affected by the treatments. The results obtained from the Visual MINTEQ Geochemical model showed that the highest amount of the free form of zinc $\left(\mathrm{Zn}^{2+}\right)$ was obtained at the level of $300 \mathrm{mg} . \mathrm{kg}-1$ of carboxyl iron oxide nanoparticles. Also, the experimental treatments significantly influenced the concentration of Zn-DOM species. The positive and significant correlation between $\mathrm{Zn}^{+2}$ and $\mathrm{Zn}$ - DOC species with the concentration and total $\mathrm{Zn}$ uptake of wheat indicated that these pools of Zn could be liable species in soil. The results of this study, therefore, showed that the application of functionalized iron oxide nanoparticles could help to improve soil conditions in order to increase the zinc availability for plants.
\end{abstract}

Keywords: Nanoparticles, Dissolved organic carbon, Chemical fertilizer, Micronutrients.

1. Department of soil Science, Shahid Chamran University of Ahvaz, Ahvaz, Iran.

2. Department of Chemistry, Shahid Chamran University of Ahvaz, Ahvaz, Iran.

*: Corresponding author, Email: m.norouzi@scu.ac.ir 